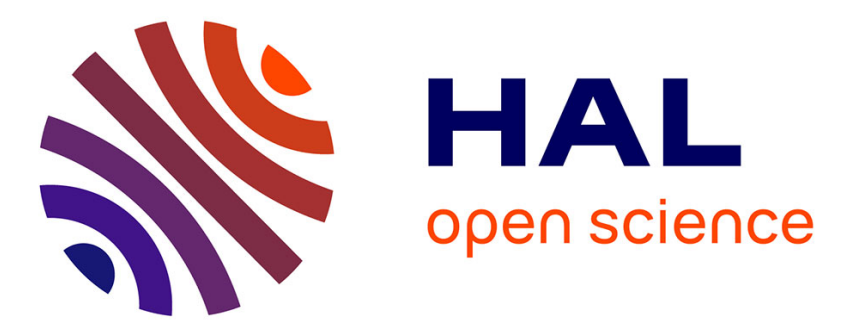

\title{
Composites and Dynamic Failures: Experimental and Numerical Solving Strategies and Solutions \\ Daniel Coutellier
}

\section{To cite this version:}

Daniel Coutellier. Composites and Dynamic Failures: Experimental and Numerical Solving Strategies and Solutions. Serge Abrate; Bruno Castanié; Yapa D. S. Rajapakse. Dynamic Failure of Composite and Sandwich Structures, 192, pp.611-643, 2013, Solid Mechanics and Its Applications book series, 10.1007/978-94-007-5329-7_14. hal-01654040

\section{HAL Id: hal-01654040 \\ https://hal.science/hal-01654040}

Submitted on 2 Dec 2017

HAL is a multi-disciplinary open access archive for the deposit and dissemination of scientific research documents, whether they are published or not. The documents may come from teaching and research institutions in France or abroad, or from public or private research centers.
L'archive ouverte pluridisciplinaire HAL, est destinée au dépôt et à la diffusion de documents scientifiques de niveau recherche, publiés ou non, émanant des établissements d'enseignement et de recherche français ou étrangers, des laboratoires publics ou privés. 


\title{
Composites and Dynamic Failures: Experimental and Numerical Solving Strategies and Solutions
}

\author{
Daniel Coutellier
}

\begin{abstract}
The constraints related to structures design in the field of transportation are increasingly complex in order to comply with safety standards. Composite materials being increasingly widespread within these structures, their behavior must therefore be more accurately mastered. Current numerical tools can now permit an accurate simulation in the static field, but concerning fast transient problems, the available numerical methods are not optimal yet. Starting from concrete cases, this chapter introduces problem solving strategies. A procedure is then presented to improve numerical simulations in the field of rapid dynamics. It includes the establishment of experimental protocols to assist in a thorough understanding of materials behavior. These experimental studies can then provide models, laws and methodologies to better simulate the behavior of composite structures under dynamic load. However experimentation is sometimes complicated by the size of structures. The similitude techniques can then provide a solution. Similitude techniques are used to study composite materials subjected to impact. We propose here an approach allowing modeling and numerical simulation validated on an industrial case.
\end{abstract}

Keywords Rapid dynamics • Composite $\cdot$ Damage $\cdot$ Scale effect

\section{Introduction}

Structural design in the transportation field must comply with numerous constraints in order to meet both environmental and recycling criteria. Increasingly integrating features within components contributes to on-going weight reduction

D. Coutellier $(\triangle)$

LAMIH UMR CNRS 8201, University Lille Nord de France, Valenciennes, France

University of Valenciennes, F-59313 Valenciennes, France

e-mail: daniel.coutellier@univ-valenciennes.fr 
in order to increase the capacities and reduce consumption while retaining, or even improving, the mechanical performance. These primary objectives result in increased use of composite materials, plastics and alternative new materials and sandwich construction. Even though those materials have been used in aeronautics for quite a long time featuring some $15 \%$ (in mass) of composites on the A320 since 1988 and 25\% for the Airbus A380. The new Boeing 787 and the future Airbus A350 reach the ratio of $50 \%$. In the automotive field, the $25 \%$ score has by now been reached on some space-wagons. And today, the ULIMAT project (Innovative Use of New Materials in Railway Design) of the Itrans cluster, on a global scale, aims at validating the use of new materials (Composites, foams, metallic materials, brand new steels, steel/polymers sandwich structures) in order to build up a multi-material body-shell aiming at using the most adapted material for a specific function in order to reach a $20 \%$ mass reduction, a $20 \%$ reduction in the number of parts making up a body and a 50\% decrease in the assemblytime. As regards the behavior field in rapid dynamics, the solutions available are not perfect yet. Right now major research and development themes in this domain are studied [1-3]. A procedure proposed to help improve the numerical simulation tools in the field of rapid dynamics is then introduced for 2D composites. It includes the establishment of experimental protocols to assist in a thorough understanding of materials behavior. However experimentation is sometimes complicated by the size of structures. Similitude techniques can then provide a solution to reduce the cost and study time. First, we present a variant of the similitude techniques for the study of composite materials subjected to impact. Introduced by Jackson [4] and Simitses [5] for linear cases, this method has been extended for rapid dynamic cases [6]. In the second part, we propose an approach for the numerical simulation of rapid dynamic phenomena. The modeling of damage, of delamination, of strain rates is proposed here and contributes to the simulation of complex phenomena. The application to an industrial case of a composite bonnet allows to validate this approach.

\section{A Few Examples of Fracture of Composites Materials}

The study of structures submitted to shocks and impact is rather complex whenever the materials used are composites. Indeed, the failure modes encountered are wideranging and mainly depend upon the choice of the material and its components. As a result, they are still poorly mastered and are right now difficult to reproduced in terms of numerical simulation. Figure 1 displays the complexity of the fracture modes encountered in the case of energy absorbers, in-built within the floor of aeronautic structures submitted to axial compression [7, 8]. Delamination between the laminated material plies, fiber splitting within the same ply present many difficulties in terms of repeatability in numerical models in order to determine exactly the value of the energy absorbed by overall deformation. With composite structures, the assembly areas are equally critical and complex. Figure 2 (Postec 


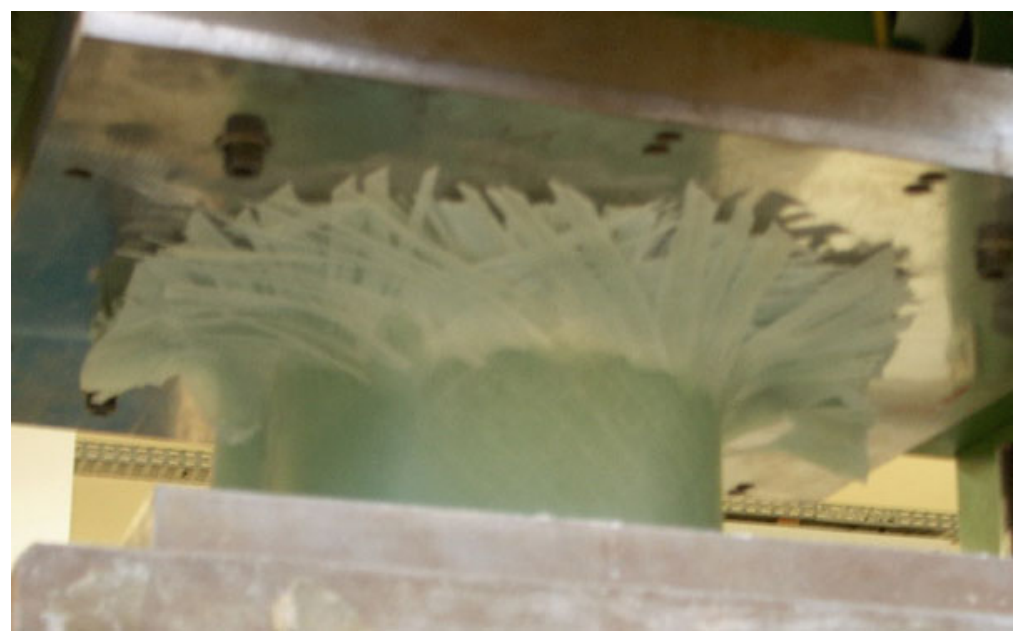

Fig. 1 Fracture mode of an energy absorber

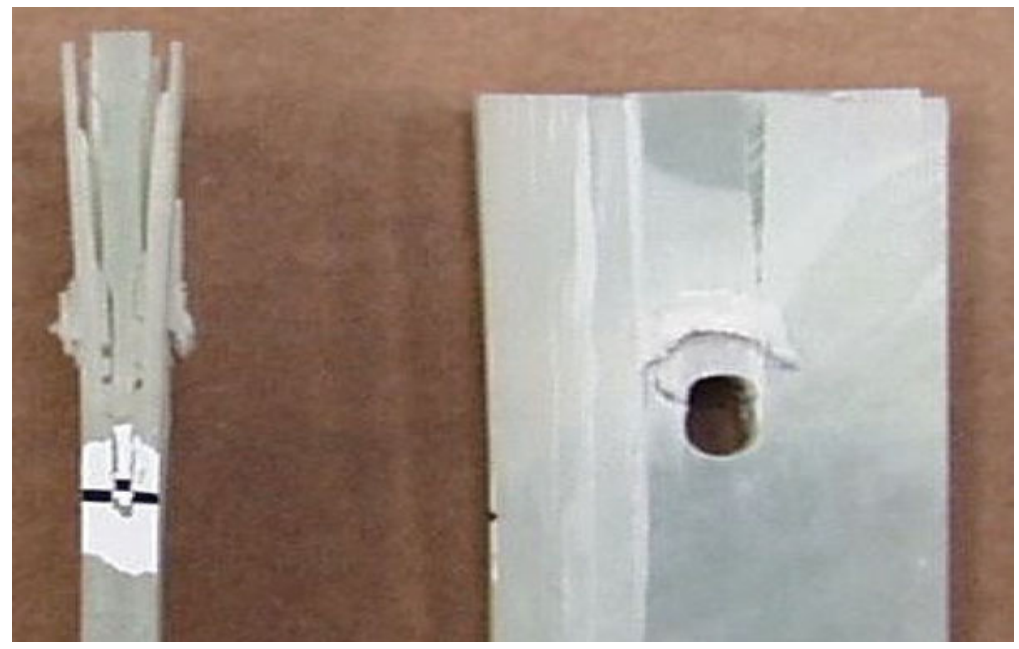

Fig. 2 Fracture mode during the bearing process of a $[0 / 45 / 90 /-45]_{\mathrm{s}}$ composite assembly

et al. [9]) shows the desirable fracture mode via bearing rupture in order to consume little energy within link fracture. Figure 3 (Provost et al. [10]) shows the fracture mode after impact behavior of a composite solution made with warp interlock fabric used in hard protection as armored shield of vehicles. The assumed delamination process of the $3 \mathrm{D}$ textile structure tends to be more complex. This failure kinematics is paramount in order to contribute to an overall prediction of the failure process. It is therefore essential not only to be able to reproduce it in numerical simulations but also first and foremost to understand it. Many other 


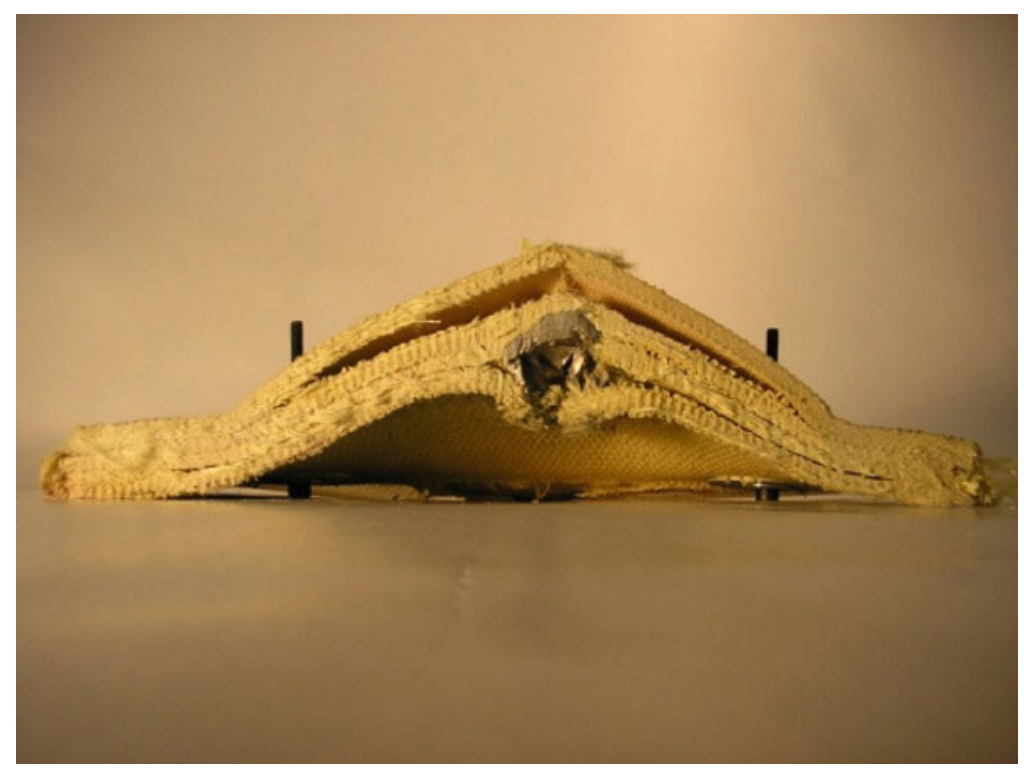

Fig. 3 Fracture mode after impact behavior of a warp interlock fabric composite

examples might be given in all fields and the limits are often associated with the development tools available during the design phase [11-13]. For instance, some car manufacturers are now considering multi-material composite bonnets which would permit to reduce injuries, more particularly, head-injuries in the case of an impact, in their efforts to anticipate new regulations. Again, the simulation softwares are far from being efficient and, right now, numerous tests [14] (Fig. 4) are required in order to permit the test/computations calibration to refine the technological developments. The tendency to lighten structures requires to use more composite materials in the future design.

The composite material complexity is due not only to its components structure but also to its various processes, to its durability, to its deformation, damage and fracture modes in the case of an impact or a crash. In order to master these phenomena, experimental campaigns are necessary. They represent a non-negligible cost and they may be somehow difficult to implement should the structure size be important and the price of the structure. Indeed, if it is fairly easy and usual to cashtest an automobile, it is quite a different story for a train-coach or a plane. In this particular case-study, a scaled-down test helps reduce the costs under the condition that it is possible to reproduce the accurate behavior, which is here far from being valid whenever the structures are made up with composites and the loading mode is rapid dynamics, therefore restricted to the non-linear field. For over a decade, studies have been carried out at the LAMIH in order partly to answer the questions arising during the crash, in the field of metallic/composite materials behavior, while developing similitude applications. For composite materials, specific items have 


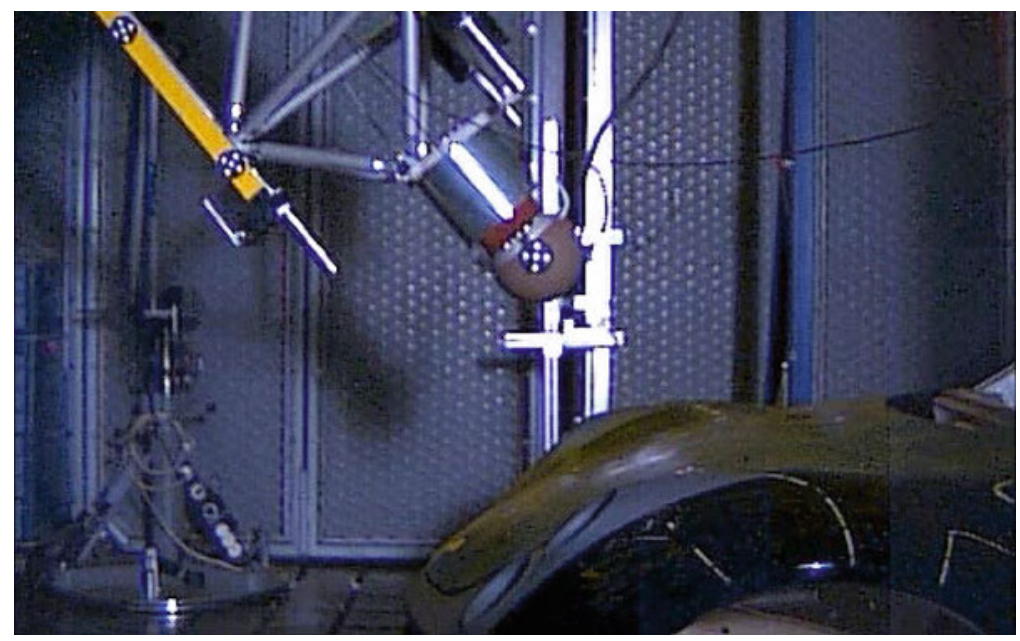

Fig. 4 Example of a pedestrian collision test on bonnet (Courtesy: Daimler)

been developed in industrial codes $[15,16]$, methodologies have been implemented in order to integrate precise damage modes [17], similitude methodologies have been suggested in order to permit the study of scaled-down composite structures [18]. Those studies are still going on in order to bring a contribution to the improvement of virtual prototyping tools and we hereby present two examples of resulting applications. One concerns the development of a similitude method to determine the real scale behavior starting from scaled-down structures. The second concerns the studies carried out with a car-manufacturer for the analysis of a pedestrian's head impact onto a front car-bonnet.

\section{Analytical Model for Similitude Analysis}

Despite recent improvements achieved in numerical simulation [19-21], such phenomena as delamination or strain rate influence are still poorly represented and are the aims of numerous studies nowadays. Experimentation is consequently the only reliable validation method but its setting up can give rise to some problems of cost, of place or of equipment especially for airplane or railway structures. Tests on scaled down structures seem to be the obvious solution. But it also leads to a lot of problems such as the preservation of the assembly way, of the manufacturing process and of the mechanical properties. Similarity laws already exist for traditional materials [22] but there is nothing about composite materials under dynamic loading. However laminated composites still present an issue: to preserve the ply material and reduce the specimen thickness, it is unavoidable to reduce the number of plies. Some re-arrangement techniques exist for this thickness 


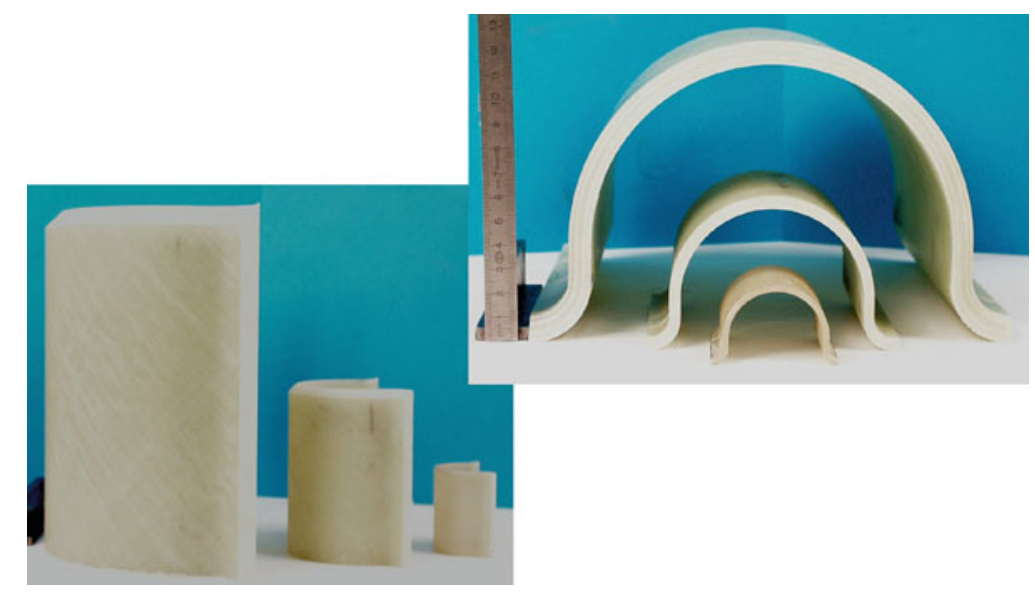

Fig. 5 Structures featuring three different scales $(1 ; 1 / 2 ; 1 / 4)$

reduction $[4,5]$ but they originate only from geometrical considerations, they are not applicable to the whole stacking sequences and they do not preserve all the mechanical properties of the structure. Moreover, modifying the ply number makes it impossible to use total similarity (there is a distortion between the prototype ply number and the scaled down model one). So, the aim is to apply partial similarity on a determined structure under a specific loading minimising the distortion effects, and then, to extend the method to more complex structures. Static and dynamic tests have been performed on specimens (Omega structure (Fig. 5)) currently used in the design of aeronautic structures to absorb energy.

The objective of these techniques is a structure scale reduction; however, within our study, these techniques have been used in an inverse way, that is to say applied gradually on the $1 / 4$ scaled models then on the $1 / 2$ scaled models and finally on the prototype. The similitude techniques, developed initially by Jackson [4] are the following ones:

- the first one, consists in defining a first stacking sequence made of $\mathrm{n}$ plies $[+\theta /-\theta]$, then defining the following one by doubling each ply in order to obtain a final laminate made of $2 \mathrm{n}$ plies $\left[+\theta_{2} /-\theta_{2}\right]_{\mathrm{s}}$. This similitude is very interesting because it permits directly to have consistent stiffness (in-plane tension and compression) and flexion modulus,

- the second one, consists in symmetrising the initial stacking sequence,

- the third one, leading from the laminate $[+\theta /-\theta]_{\mathrm{s}}$ to the final laminate $[+\theta /-\theta]_{2 \mathrm{~s}}$, is performed by symmetrising the initial sequence twice. As for the first technique, it allows a correct setting of the in-plane modulus, but not of the bending modulus.

A static INSTRON machine can be used as well in traction as in compression. Its load capacities are adaptable $(2,5,10,20,50,100 \mathrm{kN})$ according to the testing speeds applied $(0.1 \mathrm{~mm} / \mathrm{min}$ until $500 \mathrm{~mm} / \mathrm{min})$. An in-house developed hydraulic 
Fig. 6 Comparison of fracture modes at different scales

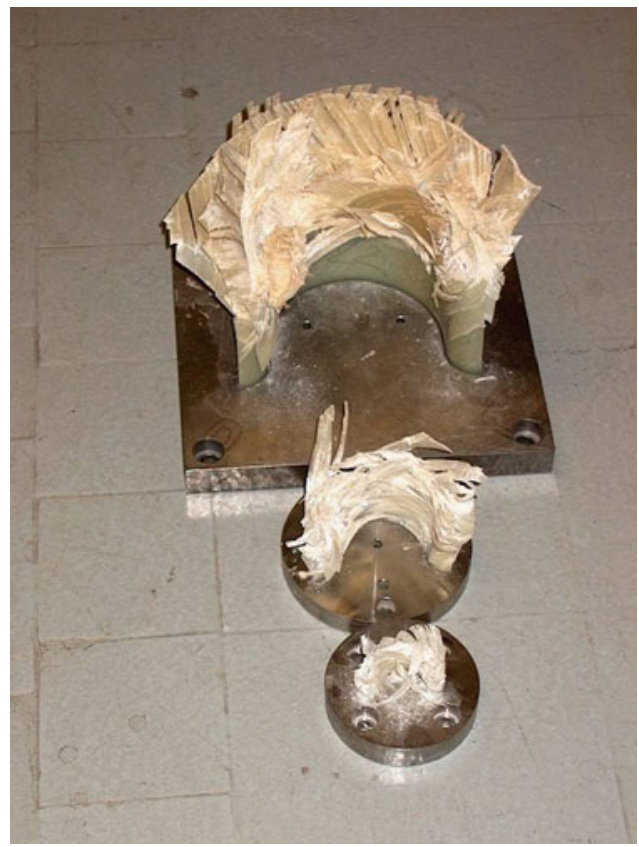

press has been used for the one half and one scaled specimens. This machine has a $1,000 \mathrm{kN}$ compression load capacity and is composed of a hydraulic jack with a maximum $100 \mathrm{~mm}$ displacement; that explains why the total crush displacement is limited to this value. Its speed range extends from 10 to $100 \mathrm{~mm} / \mathrm{min}$.

For the one-fourth scaled specimens, dynamic tests have been performed on an in-house designed hydraulic machine composed of a dynamic jack supplied by a pressure of 350 bars and a $150 \mathrm{l} / \mathrm{h}$ flow rate. Its load capacities are $50 \mathrm{kN}$ in dynamics and $69 \mathrm{kN}$ in statics. Its maximal speed reaches $10 \mathrm{~m} / \mathrm{s}$ for a maximum $250 \mathrm{~mm}$ displacement. For larger specimens (scale 1/2 and 1), tests have been carried out in a drop tower designed by C3T (University of Valenciennes) and permits to test in free fall conditions, a maximum mass ranging from 100 to $700 \mathrm{~kg}$, from a variable height between $80 \mathrm{~cm}$ and $4 \mathrm{~m}$.

For each laminate or test speed tested, at least three tests has been performed. The main fracture mode observed in the tests performed consists of a peeling mode. Plies progressively and symmetrically separate in most cases, on both sides of the middleplan of the structure. This mode has already been described in previous studies [5, 23-25]. This fracture mode, specific to composites, has been shown not to be influenced either by the structure dimensions or by the loading speed and by the stacking sequence tested. The Fig. 6 presents a comparison between different scales.

This research on similitude uses the dimensional analysis approach coupled with experimental observations for distortion detection. An empirical polynomial model was developed to predict the evolution of the result as a function both 
of the scale and of the distorted parameters. This approach seems to be feasible since studies about the scale-effects, available in literature, describe their evolution as being both monotonous and continuous if the latter is not linked with the emergence of the phenomenon for a specific scale which goes unobserved in all other cases. Therefore, this method consists in carrying out the scaled-down models and experimental conditions dimensioning starting from a dimensional analysis. The latter permits the detection of parameters failing to be scaled up. Then, starting from tests on scaled-down models, a polynomial is identified by performing an extrapolation using the distorted parameters as well as the overall (geometric) scale factor, as unknown factors, in order to bring to the fore the scale effects. This step requires to carry out tests on several configurations and several scales of scaled-down models. The number of tests to be performed mainly depends on the polynomial degree for each unknown factor and therefore on the phenomena brought into play. However, the dimensional analysis provides the polynomial degree for a distortion-free scale factor and it therefore makes sense to suppose that this degree is but slightly changed by the distortion effect. Furthermore, a phenomenological study may enable to put forward hypotheses as regards the evolution of the result in function of the distorted parameters as it is the case for energy absorbers (Figs. 1 and 6) with $\mathrm{a}+$ or $-45^{\circ}$ configuration.

Generally speaking, there are two main methods to determine similarity relations between a scale 1 prototype and a scaled-down model. The direct method consists in using an analytical model representing the test. Comparing the equations colloquial with the parameters of the prototype and those of the scaled-down model, relations which directly link the two structure scales are obtained. In this case the phenomena are too complex and, as a result, there does not exist any really reliable analytical model. So, this method is not usable for this kind of structures. The second method consists in identifying all the parameters likely to exert an influence. Then, we apply the Vashy-Buckingham П theorem [26]: "an equation (E) linking (n) physical quantities can be transformed into an equation $\left(E^{\prime}\right)$ linking $(n-p)$ dimensionless quantities $\pi$, where $\mathrm{p}$ is the maximum number of quantities dimensionally independent in $(\mathrm{E})$ considered." The similarity relations are obtained equalizing each $\pi$ number from the prototype and the scaled-down model. Generally, during the setting up of the $\pi$ numbers, an effort is made to use specified ones with a particular meaning. In the case of a structure crash, Cauchy's number allows to conserve the proportions between the inertial effects and the elastic forces.

$$
\Pi_{\text {Cauchy }}=\frac{\rho V^{2}}{E}
$$

The problem in this case is the very large number of parameters and the fact that influent parameters are very difficult to identify. However, a dimensional analysis of the main parameters, supposed to be the most influent, has permitted not only to dimension the specimens but also to make a first comparison of the experimental results. 
Table 1 Evolution of some quantities from Cauchy's similarity law

\begin{tabular}{lll}
\hline Variables & Prototype & Model \\
\hline Acceleration & $\mathrm{A}$ & $\mathrm{A} / \beta$ \\
Stress & $\sigma$ & $\sigma$ \\
Strain & $\varepsilon$ & $\varepsilon$ \\
Density & $\rho$ & $\rho$ \\
Displacement & $\delta$ & $\beta \delta$ \\
Length & $\mathrm{L}$ & $\beta \mathrm{L}$ \\
Kinetic energy & $\mathrm{Ec}$ & $\beta^{3} \mathrm{Ec}$ \\
Force & $\mathrm{F}$ & $\beta^{2} \mathrm{~F}$ \\
Mass & $\mathrm{m}$ & $\beta^{3} \mathrm{~m}$ \\
Young modulus & $\mathrm{E}$ & $\mathrm{E}$ \\
Time & $\mathrm{T}$ & $\beta \mathrm{T}$ \\
Impact velocity & $\mathrm{V}$ & $\mathrm{V}$ \\
\hline
\end{tabular}

The use of the Vashy-Buckingham $\Pi$ theorem permits to obtain several $\pi$ numbers including Cauchy's one. For each X parameter, a scale factor is defined as follows:

$$
\beta_{X}=\frac{X_{\bmod e l}}{X_{\text {prototype }}}
$$

The equalization of the $\pi$ numbers from the prototype and the scaled-down model permits to express the scale factors relative to all parameters in function of one of them. Generally, the parameter chosen is the length and its scale factor is simply noted $\beta$. Some examples of relations obtained are plotted in Table 1. It is interesting to see that, in this case, the test velocity is not modified by the scale change.

Cauchy's similarity law foresees to conserve all mechanical properties which suggests to keep the same material with the same fibre rate to manufacture both the prototype and the scaled-down models. This induces ply thickness conservation. So, the first distortion is obvious because there is an un-scalable geometrical parameter. Consequently, the only way to reduce the stratified structure thickness is to reduce the ply number. The dimensionless numbers such as the ply number or the interface number between plies with different orientations are directly $\pi$ numbers. They should be the same both for the prototype and the scaled-down models. The standard choice is to conserve the material making up plies and to modify the ply number and therefore the stacking sequence. This modification can also induce a modification of the non-linear behavior of the composite. A second more specific distortion for tests carried out with the drop tower has been detected: the gravity acceleration cannot be modified. But some tests carried out at $4 \mathrm{~m} / \mathrm{s}$ with one fourth scale specimens with a 12.9 and a $21.5 \mathrm{~kg}$ dropped mass have shown there is no influence of the impactor weight on the force plateau. To sum up, some distortions have been detected between the prototype and the scaled-down models but they seem to be unavoidable. In addition, without equations describing the system, it is impossible 
to determine exactly the effects of these distortions. As a consequence, another approach is necessary to obtain relations permitting to foresee the results of a composite material structure crash from those of crashes of scaled-down models.

\subsection{Polynomial Construction for Omega Structure Crashes}

The dimensional analysis has brought to the fore a ply-number distortion (hereby, the structure is studied at a mesoscopic scale) which results most of the time into a distortion at the interface level between $+45^{\circ} /-45^{\circ}$ oriented plies. Those interfaces are generally the delamination location since they undergo shearing constraints due to the orientation difference of the adjacent ply fibers, which favors its initiation. In addition, the branch flexion makes the surfaces thus created relatively slide, thus inducing frictional forces. The delamination and the frictional phenomena between delaminated plies contribute towards energy absorption, therefore the effort withstanding the structure crunch must linearly depend on the interface-number between differently oriented plies. As a result, the medium level effort value can then be stated via the following formula:

$$
F_{p a l}=A_{0} n+B_{0}
$$

Where $\mathrm{n}$ stands for the interface number between $+45^{\circ} /-45^{\circ}$ oriented plies, $\mathrm{A}_{0}$ and $\mathrm{B}_{0}$ are empirical coefficients depending on the scale. By studying the $\mathrm{A}_{0}$ coefficients relative to each scale, the terms seemingly evolve with the overall squared scale factor. This dependence in $\beta^{2}$ does not come as a surprise since $\beta^{2}$ is the force scale factor according to Cauchy's similitude law. The efforts related to frictions between adjacent plies together with the effort linked with the inter-laminar cracking is unaffected by distortions. The interface and the frictional coefficients are indeed retained by the scale change since the material making up the plies is quite identical. It is therefore quite predictable that those phenomena do not entail a scale effect. The Eq. (3) can therefore be re-formulated as follows:

$$
F_{p a l}=A n \beta^{2}+B_{0}
$$

The A coefficient, thus determined, features a weak amplitude variation in function of the scales of the structure under study, which may be accounted for by the experimental scattering. By imposing the A coefficient the determined value by averaging the A coefficients relative to the series of points originating from each scale, a linear increase of $\mathrm{B}_{0}$ term in function of the overall scale factor can be highlighted.

The Eq. (4) thus becomes:

$$
F_{p a l}=A n \beta^{2}+B \beta-C
$$


$\mathrm{A}, \mathrm{B}$ and $\mathrm{C}$ being empirical coefficients independent from $\mathrm{n}$ and $\beta$, are therefore constant whatever the stacking sequences and the omega structures scales (Fig. 5) Some phenomena can be related to the different polynomial coefficients (5). Indeed, the resistance efforts corresponding to the phenomena cropping up at the interface level, such as de-lamination or inter-ply friction, are related to A term as above demonstrated. The other main phenomenon in the energy absorption process being the resistance to ply-bending. It seems therefore logical to associate it with $\mathrm{B}$ and $\mathrm{C}$ terms, more particularly as the latter feature a scale effect. Now, the distortion over the interface number must entail consequences on the resistance of samples subjected to flexion. However, those terms remain constant whatever the interface number. The inter-laminar crack number still alters the structure resistance in flexion by splitting the structure into several independent ply clusters, within the material thickness. Also included in A terms an item corresponding to the effort collapse related to delamination. In other words, A term corresponds to the sum of the effort connected with delamination, of the one related with friction and to the resistance collapse in bending triggered by delamination, whereas $\mathrm{B}$ and $\mathrm{C}$ coefficients correspond to the maximum resistance in bending of the delaminationfree plies, to the impactor/structure friction and to the longitudinal cracking process. The scale effect therefore concerns the ply resistance in bending or the longitudinal cracking process. Now, both phenomena certainly feature a strong interaction since the ply cracking cuts the structure into strips, which alters it quadratic moment and therefore its resistance in flexion. Likewise, longitudinal cracking is caused by tensile/compression constraints which appear whenever the branches bend. Consequently, whatever the phenomenon submitted to this scale effect, the ply resistance in bending is necessarily affected. Whatever the approach, even though some observations still remain difficult to explain, the methodology explained throughout this paragraph has permitted to reach polynomial relation (6). This empirical expression cannot be explicitly connected with the samples' geometrical properties or with the material mechanical properties. Yet, it can be used in order to determine the step by step real-scale sample efforts since it provides this value in function of parameters characterizing the samples.

\subsection{Scale Change Relation Determination}

In the previous paragraph, a polynomial was built up starting from the basis of a dimensional analysis, of phenomenological observations and from measurement performed on scaled-down models. This polynomial (5) permits the direct computation of the step effort average values whatever the interface number featured by the laminated material stacking sequence and the structure scale under study. In addition, by using this direct method, this polynomial can be used to determine the scale change relations which will then be applied to the force/displacement graphs recorded during tests on scaled-down models in order to obtain those 


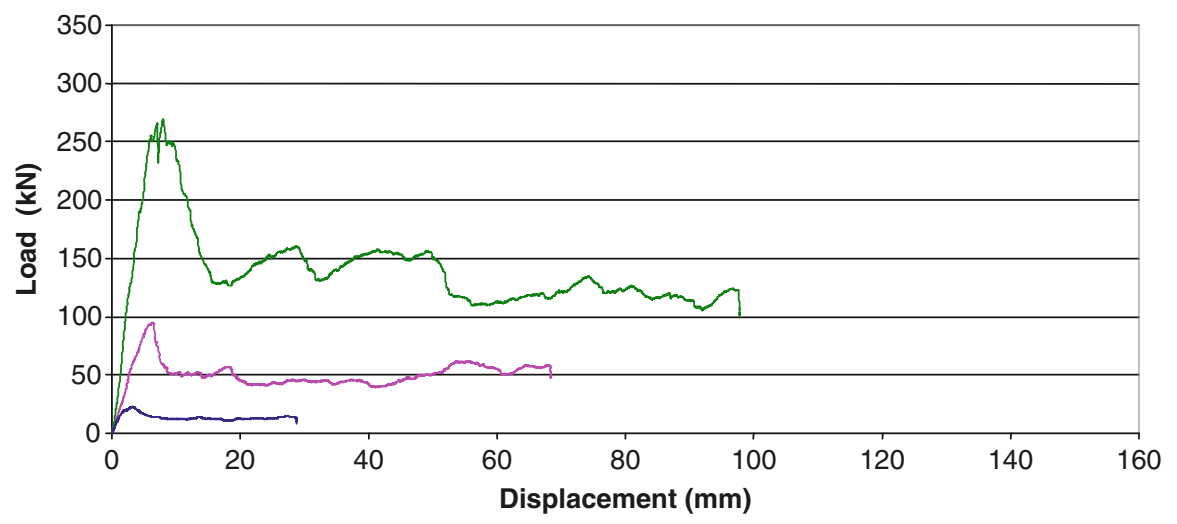

- Scale 1/2 with 6 interfaces - Scale 1 with 6 interfaces - Scale 1/4 with 2 interfaces

Fig. 7 Experimental curves for three scales

of the prototype. Let $\mathrm{F}_{\mathrm{pal}}[\beta, \mathrm{n}]$ and $\mathrm{F}_{\mathrm{pal}}\left[\beta^{\circ}, \mathrm{n}^{\circ}\right]$ be the polynomial expressions corresponding to a $\beta$ scale structure, respectively $\beta^{\circ}$, and featuring $\mathrm{n}$ interfaces, respectively $\mathrm{n}^{\circ}$, between $\pm 45^{\circ}$ oriented plies. The polynomial relative to one configuration can then be expressed in function of the one corresponding to the other configuration, as follows:

$$
\begin{aligned}
F_{p a l}\left[\beta^{\circ}, n^{\circ}\right]= & F_{p a l}[\beta, n]\left(\frac{\beta^{\circ}}{\beta}\right)^{2}+A \beta^{\circ 2}\left(n^{\circ}-n\right) \\
& +B \beta^{\circ}\left(1-\frac{\beta^{\circ}}{\beta}\right)-C\left(1-\left(\frac{\beta^{\circ}}{\beta}\right)^{2}\right)
\end{aligned}
$$

It is worth noting that in expression (6), the first term is identical to the one appearing within the Cauchy similitude application, the second term is used to somehow correct the distortion concerning the interface number and the last two terms permit to take into account the scale effect related with the structure crunch resistance. The prototype configuration being sought for is a priori known. It is therefore possible to apply this polynomial expression (6) to an effort/time or effort/displacement curve. The $\mathrm{x}$-axis can then be scaled by using the scale-factors resulting from the Cauchy similitude law since neither time nor displacements are affected by distortions. Figures 7 and 8 are a perfect illustration of the axial compression study-case of the energy absorbers tested in real scale.

In this part, a similitude technique was proposed to allow the study of a structure of big size with a reduced mock-up. The global behavior of structures can thus be studied. In the following part, the study of behavior of structures by numerical simulation will be proposed. For that, a methodological approach will be presented using many simple tests, by identifications and to permit the development of tools for numerical simulation. 


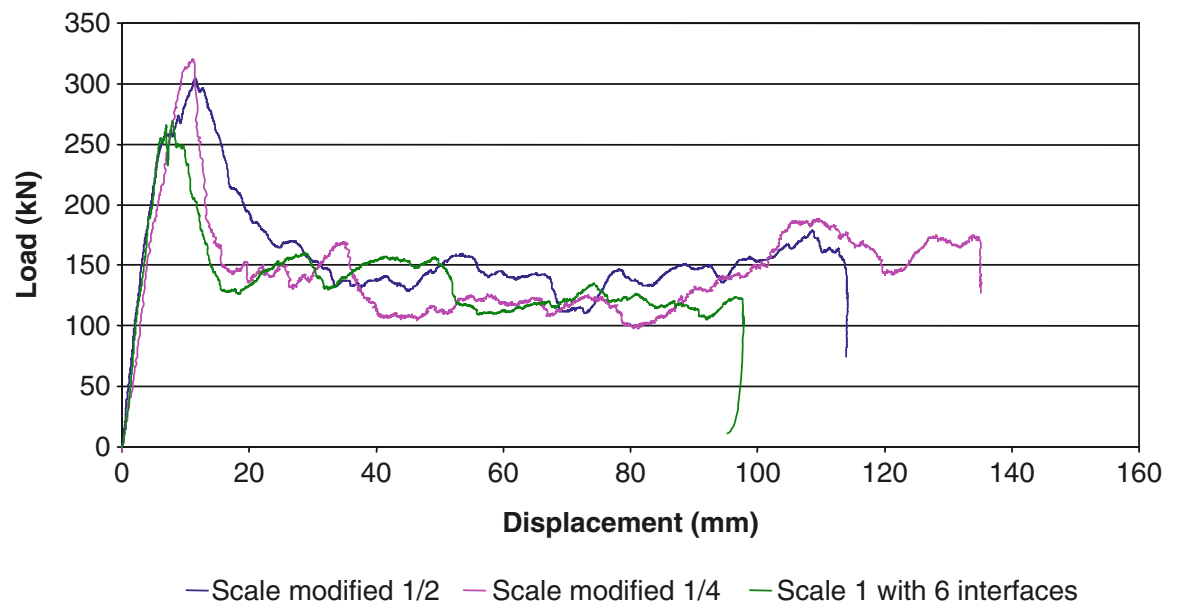

Fig. 8 Curves after similitude application

\section{Pedestrian Impact Modelling onto a Composite Bonnet}

The issues linked with numerical simulation use for severe impacts are mainly due to the complexity of the composite material. Indeed, the behavior of each composite material is specific and its thorough knowledge is paramount for a better integration into the models. On the other hand, in order to achieve a suitable composite material behavior modeling, a sufficiently significant representation scale definition (Macro, Meso, Micro) is of primary importance. In order to permit both the improvement and the development of innovative tools, for a better contribution towards an improved approach to design via numerical simulation, it seems to be a prerequisite to have an in-depth understanding of the associated physical phenomena in order to reduce the real practical tests. The methodology generally used is based upon an accurate knowledge of the composite materials, reached through experimental campaigns on simple-shaped samples, thus permitting the development of data-bases on materials. Tests are sometimes necessary when more complex behavior in 3D can be complex [27]. For example in a static case on Fig. 9, we present results obtained from the experimental study on the behavior of glass/epoxy butterfly-shaped specimens tested under pure shear and biaxial loadings using an Arcan device [28]. Notchto-notch longitudinally and perpendicularly oriented fiber samples, respectively referred to as Mat31 and Mat32 ones have been tested with different loading angles ranging from $0^{\circ}$ to $90^{\circ}$. Figure 10 presents the test configuration. A thorough analysis of the results, aimed at better understanding and explaining the fracture and damage phenomena, thus contributes to implement knowledge bases.

Those phenomena then must be translated into an already-existing or new behavior model. Thus, innovative features are defined in terms of behavior laws, of specific items or even in terms of methodologies. The validation phase is essential. 

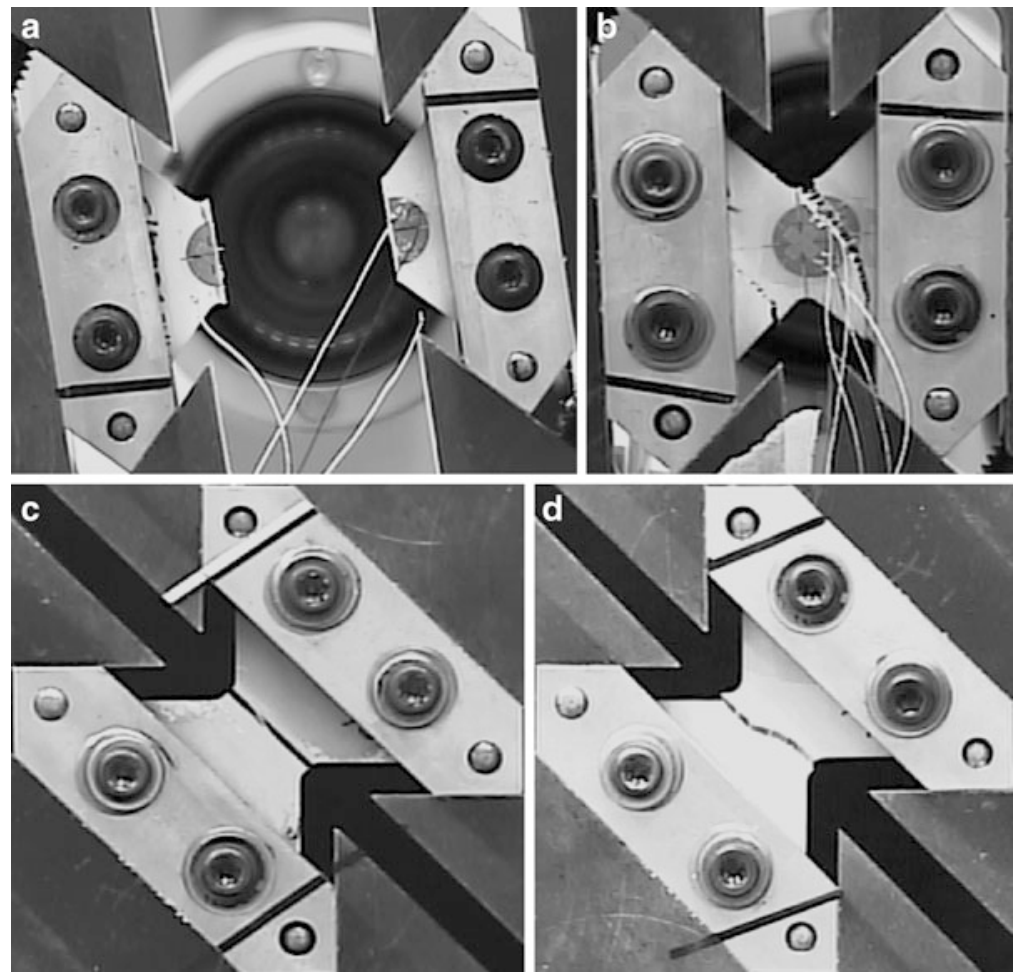

Fig. 9 Photos of fractured samples under pure shear loading of Mat31 (a) and Mat32 (b) obtained by Arcan tests Photos of fractured samples under biaxial loading $\left(\alpha=45^{\circ}\right)$ of Mat31 (c) and Mat32 (d) obtained by Arcan tests

It permits, in the first instance and within the sample scale, to reproduce the elementary material behavior. Then comes the time for validation at the scale of either a component or a structure.

\subsection{The Mechanisms Encountered During the Deformation of Composite Materials}

There are three fundamental damage mechanisms that are frequently encountered in the plies of a laminated material (resin-fiber); these are: fiber-matrix debonding, cracking of the matrix and the failure of fibres (Fig. 11). Between differently oriented plies these primary mechanisms generate another type of mechanism, known as delamination, which causes interlaminar cracking.

These mechanisms can be incorporated into computation codes in several ways. One possibility is a macromechanical approach in order to deal with the overall 
a

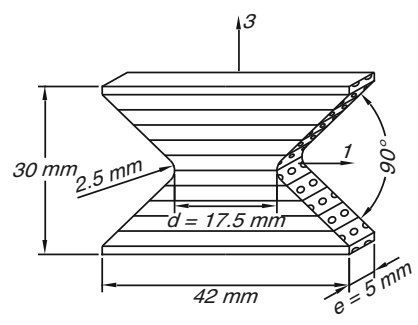

b

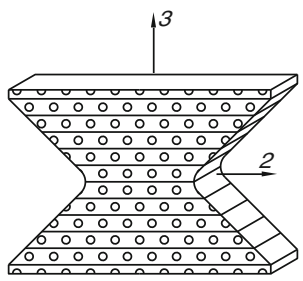

C

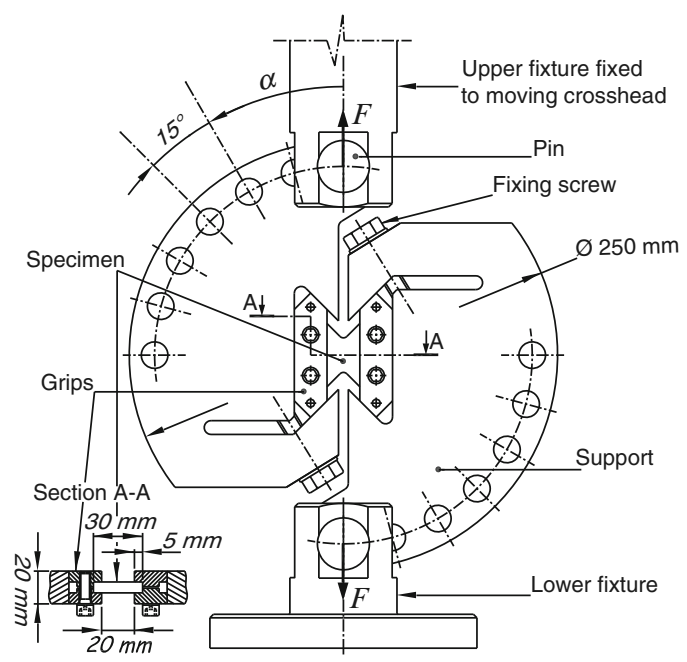

Fig. 10 Schematics of Mat31 (a) and Mat32 (b) specimens: notations with stacking orientation and local coordinates. Arcan test setup in pure shear mode (c)

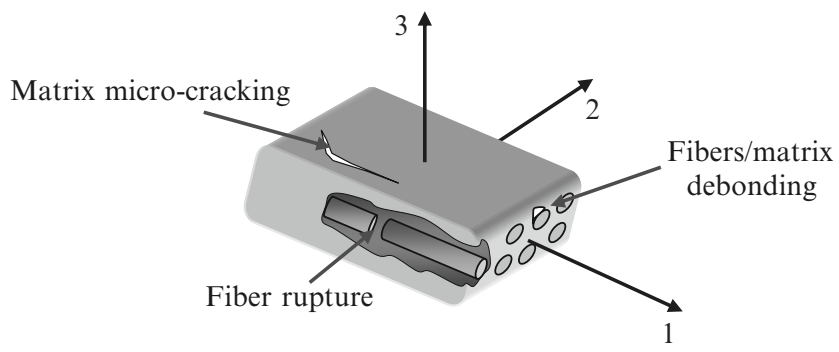

Fig. 11 Damaging modes within the elementary ply

processes taking place. A micromechanical approach can also be considered which provides a detailed understanding of localized phenomena. The approach adopted here is based on a mésomodèle [29], which means that the phenomena can be homogenized at the ply level. The basic model which is implemented within the computation code is that developed by Ladevèze [29]. Originally, this expressed fiber-matrix debonding and the cracking of the resin respectively by means of two damage variables associated with the shear and transverse moduli. A third parameter was then introduced that defined the yield point of the fibers. Depending on the materials used to make the composite (kind of fiber, resin, manufacturing process...), it was then necessary to introduce other characteristics, for example the anelastic effect of the resin, the effects of strain rate, the difference in tensile and compressive behaviour, etc. The research conducted at LAMIH has made a 

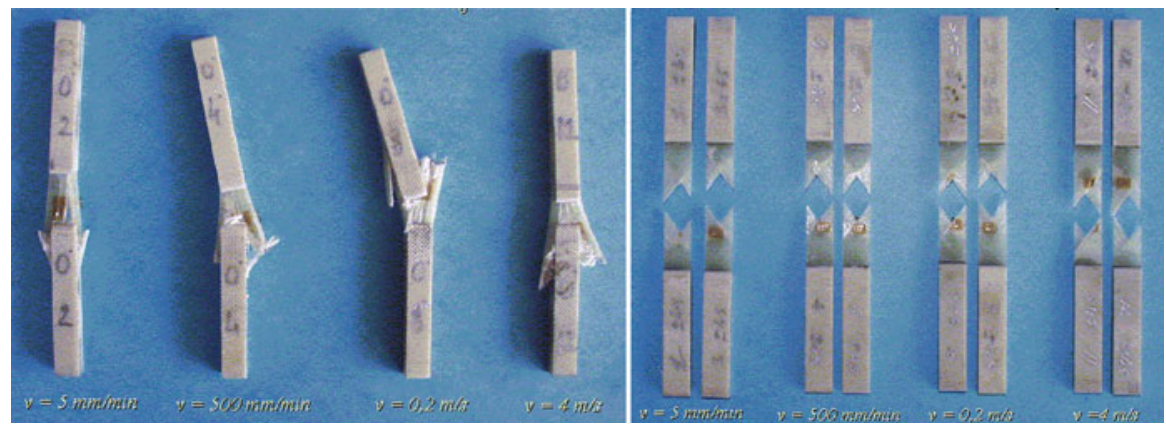

Fig. 12 Examples of failure of specimens tested experimentally (compression and tensile tests on different specimens)

significant contribution to the original mesomodel. The detailed account of these contributions with regard to the points mentioned above is to be found in a number of theses [30-32].

\subsection{Experimental Characterization}

To supply the models and methodologies with data, an experimental characterization campaign was required, with the aim of understanding the behavior of the composite and the associated damage processes. Static and dynamic studies were conducted on configurations of laminates of specified orientation in order to ascertain the tensile and compressive behavior of the material and its components (Fig. 12). Between three and five specimens were prepared and tested for each test, so as to ensure a minimum amount of dispersion and the validity of the values obtained. The dynamic tests were generally performed at different velocities of loading, so it was possible to quantify the influence of the strain rate, which is often important in the case of crash phenomena.

Strength tests were also performed on the interfaces between plies ARCAN test (Fig. 9) and DCB type test (Fig. 13) to characterize the interface and provide an insight into delamination phenomena [33]. These tests, which were also conducted on several specimens, had to be performed with great care and it was important for the specimens to resemble real materials, in particular resulting from the same manufacturing processes.

\subsection{New Possibilities Provided by the Behavior Models}

The research conducted in the laboratory was the outcome of work on the modeling of multimaterials (GLARE) that were in use a few years ago for aeroplane fuselages. 


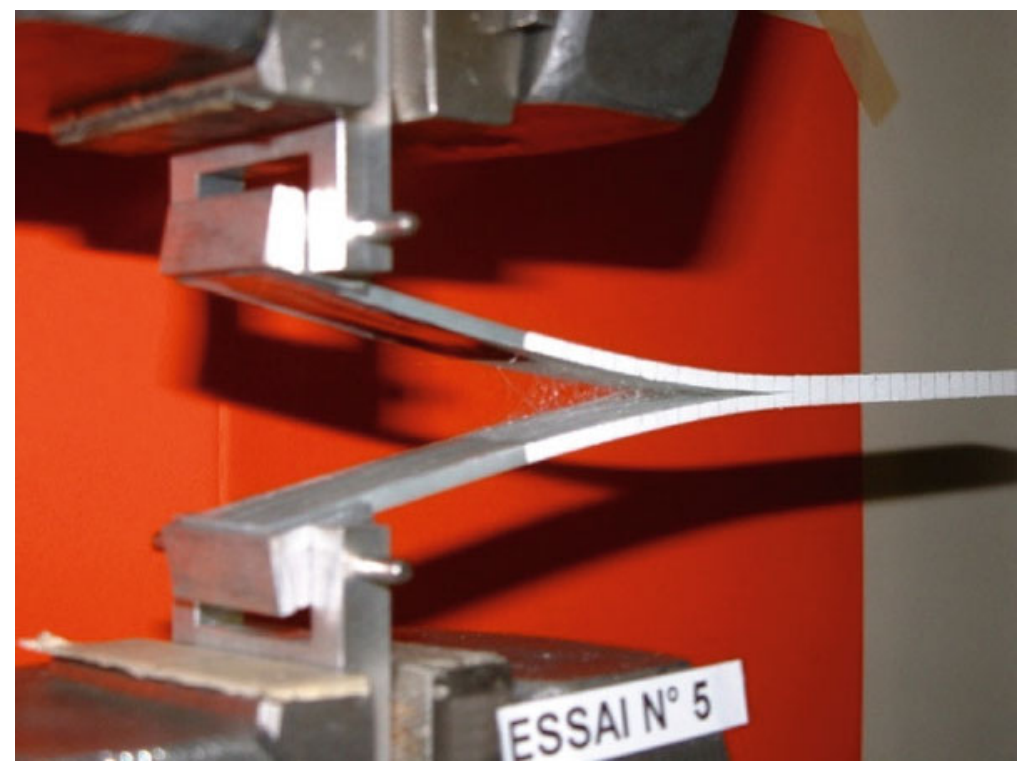

Fig. 13 DCB test

Composite structures are very frequently subjected to severe local stresses which do not necessarily cause visible damage of the surface of the material but which lead to major internal damage which often endangers safety and the survival of components. It was in order to provide a partial solution to this problem that a multi-layer multimaterial element was developed [15], for the impact modelling of laminates made up of materials which differ very greatly in their behavior. The multi-layer element is based on a Mindlin-Reisser finite element shell taking into account the effect of transverse shear and with bilinear interpolation functions. Between one and four integration points can be used in each ply. Many studies [30] have validated this finite element, which has been incorporated into the PAMCRASH ${ }^{\mathrm{TM}}$ industrial software. After this initial stage, in order to make improvements which take account of the principal behaviors of a composite material consisting solely of fibers and an organic matrix, the basic models [29] in the computation code were extended in order to reproduce behaviors which are close to reality. This illustrates the influence of taking certain phenomena into account or not.

Damage is taken into account by two scalar variables $\left(d\right.$ and $\left.d^{\prime}\right)$. The parameter $d$ quantifies the damage which comes from the dissociation between fibers and matrix whereas the parameter $d^{\prime}$ is related to the damage due to the micro-cracking of matrix parallel to the direction of fibers (Fig. 11). That is the reason the parameters $d$ and $d^{\prime}$ are applied respectively to shear and transverse modulus. However, distinguishing between tensile and compressive transverse responses is required. Indeed, micro-cracks grow when the composite ply is under tensile transverse loading, but they close up in the other case. Moreover, modeling also includes the 
rupture of fibers. Nevertheless, this rupture rate is determined by considering the longitudinal strain limit because rupture of representative layers is brittle in most cases. So the assigned moduli are calculated from the initial shear modulus $G_{12}^{0}$ and initial transverse modulus $E_{22}^{0}$ according to:

$$
\begin{aligned}
& \left\{\begin{array}{lll}
E_{22}=E_{22}^{0}\left(1-d^{\prime}\right) & \text { if } & \sigma_{22}>0 \\
E_{22}=E_{22}^{0} & \text { if } & \sigma_{22} \leqslant 0
\end{array}\right. \\
& G_{12}=G_{12}^{0}(1-d)
\end{aligned}
$$

Expression of the elementary ply behaviour is given by (8).

$$
\left\{\begin{array}{c}
\varepsilon_{11} \\
\varepsilon_{22} \\
2 \varepsilon_{12}
\end{array}\right\}=\left[\begin{array}{ccc}
\frac{1}{E_{11}^{0}} & -\frac{v_{12}^{0}}{E_{11}^{0}} & 0 \\
-\frac{v_{12}^{0}}{E_{11}^{0}} \frac{1}{E_{22}^{0}\left(1-d^{\prime}\right)} \frac{\left\langle\sigma_{22}\right\rangle_{+}}{\left|\sigma_{22}\right|}+\frac{1}{E_{22}^{0}} \frac{\left\langle\sigma_{22}\right\rangle_{-}}{\left|\sigma_{22}\right|} & 0 \\
0 & 0 & \frac{1}{G_{12}^{0}(1-d)}
\end{array}\right]\left\{\begin{array}{l}
\sigma_{11} \\
\sigma_{22} \\
\sigma_{12}
\end{array}\right\}
$$

where : $\langle a\rangle_{+}=\left\{\begin{array}{l}a \text { if } a>0 \\ 0 \text { if } a<0\end{array} \quad\right.$ and $\langle a\rangle_{-}=\left\{\begin{array}{l}0 \text { if } a>0 \\ a \text { if } a<0\end{array}\right.$

The non-damaging thresholds $\left(\underline{Y}\right.$ and $\left.\underline{Y}^{\prime}\right)$ for the elementary layer are given by (9). The multiplication factor $b$ from (9), allows the representation of coupling between shear and transverse effects.

$$
\begin{aligned}
& \underline{Y}(t)=S u p_{\tau \leqslant t} \sqrt{\frac{1}{2} \frac{\sigma_{12}^{2}}{G_{12}^{0}(1-d)^{2}}+b \frac{1}{2} \frac{\left\langle\sigma_{22}^{2}\right\rangle_{+}}{E_{22}^{0}\left(1-d^{\prime}\right)^{2}}} \\
& \underline{Y^{\prime}}(t)=S u p_{\tau \leqslant t} \sqrt{\frac{1}{2} \frac{\left\langle\sigma_{22}^{2}\right\rangle_{+}}{E_{22}^{0}\left(1-d^{\prime}\right)^{2}}}
\end{aligned}
$$

Moreover, laws of the damage evolution are chosen as being linear:

$$
\begin{gathered}
d=\frac{\left\langle\underline{Y}-Y_{O}\right\rangle_{+}}{Y_{C}} \text { if } d<1 \quad \text { and } \quad \underline{Y^{\prime}}<Y^{\prime}{ }_{S} \quad \text { and } \quad \underline{Y}<Y_{R} \quad \text { else } d=1 \\
d^{\prime}=\frac{\left\langle Y^{\prime}-Y^{\prime} O\right\rangle_{+}}{Y^{\prime}{ }_{C}} \text { if } d^{\prime}<1 \quad \text { and } \quad \underline{Y^{\prime}}<Y^{\prime}{ }_{S} \quad \text { and } \underline{Y}<Y_{R} \quad \text { else } d^{\prime}=1 .
\end{gathered}
$$


$Y_{S}^{\prime}$ and $Y_{R}$ have been introduced to limit the evolution of non-damaging thresholds $\underline{Y}$ and $\underline{Y^{\prime}}$, in time. Indeed, ruptures can be reached even before $d$ and $d^{\prime}$ reach "one" value.

Elastic characteristics (Young's modulus, shear modulus, Poisson's ratio) and parameters $Y_{0}, Y_{C}, Y^{\prime}{ }_{0}, Y^{\prime}{ }_{C}, Y_{R}, Y^{\prime}{ }_{S}$ and $b$ result from four experimental characterization tests.

In some cases of stacking, loading, etc. the ductility of resin can have a strong effect on composite behavior. For example, if experimental conditions let a weak loading of fibers, the behavior of the resin "will be prevalent". Moreover, some studies on strain rate dependency are carried out parallel. The first conclusions point to the high sensitivity of strain rate in previous cases where ductility of resin is dominant. It motivates the search of a better description for composite ply behavior before the introduction of strain rate sensitivity. It has also decided to introduce the asymmetrical behavior frequently noticed for tensile and compressive loading in the direction of fibers. Indeed, this could provide a difference in longitudinal Young's modulus because of fiber micro-buckling, micro-defaults at matrix/fibers interface, fibers misalignments... The integration of plasticity is proposed in the following parts as well as an account of asymmetrical tension/compression behavior. Studies concerning the plasticity of the elementary ply still draw inspiration from the modeling developed by Ladevèze [29]. The elastic damage model is identical to the previously described model. However, here, the total strain is composed as a sum of elastic strain and plastic strain:

$$
\varepsilon^{\text {total }}=\varepsilon^{\text {elastic }}+\varepsilon^{\text {plastic }}
$$

Elastic domain is described owing to a criteria function $f$ chosen under a general form of Von Mises criteria, which is related to anisotropic materials. This function depends a priori on principal stresses. However, high rigidity of fibers locks plastic flow in their direction. Therefore, criteria function depends only on transverse and shear stresses. Effective stresses permit an agreement to plasticity/damage coupling:

$$
\begin{aligned}
& \tilde{\sigma}_{11}=\sigma_{11} \\
& \tilde{\sigma}_{22}=\frac{\left\langle\sigma_{22}\right\rangle_{+}}{1-d^{\prime}}+\left\langle\sigma_{22}\right\rangle_{-} \\
& \tilde{\sigma}_{12}=\frac{\sigma_{12}}{1-d}
\end{aligned}
$$

Plastic strain evolution is described in accordance with an isotropic hardening law (13). This choice is arbitrary but it allows the evaluation of resin ductility at the first approximation for dynamic studies. Moreover, it permits the simplifying of experimental characterization for newly introduced parameters.

$$
R=\beta p^{m}+R_{0} \quad\left\{\begin{array}{l}
\beta, m: \text { material constants } \\
p: \text { effective plastic strain } \\
R_{0}: \text { initial yield stress }
\end{array}\right.
$$


In consequence, criteria function is:

$$
f=f(\tilde{\sigma}, R)=\sqrt{\tilde{\sigma}_{12}^{2}+a^{2} \tilde{\sigma}_{22}^{2}}-R
$$

$\beta, m, a^{2}$, and $R_{0}$ parameters are characteristics depending on materials and evaluated experimentally.

The choice of isotropic hardening law implies that it is not necessary to add extra experimental tests. Even, $R_{0}, \beta$, and $m$ are found from the existing test on laminate $[ \pm 45]_{2 S}$, which is a "quasi-pure" shear case. So, from each load/unload cycles, $R$ and $p$ (by integration) can be found simply (15). Then linear interpolation of the curve Log $\mathrm{R}$ versus Log p gives the necessary coefficients of the hardening law.

$$
\begin{aligned}
& R=\frac{\sigma_{12}}{(1-d)}-R_{0} \\
& \dot{p}=\dot{\varepsilon}_{12}^{p}(1-d)
\end{aligned}
$$

As for weighting between transverse and shear stresses $\left(a^{2}\right)$, the different load and unload values from the cyclic tensile test on the laminate $[+45]_{8}$ allow its calculation:

$$
a^{2}=\frac{\dot{\varepsilon}_{22}^{p}\left(1-d^{\prime}\right)^{2}}{2 \dot{\varepsilon}_{12}^{p}(1-d)^{2}}
$$

During compressive loading, laminates can suffer from non-linear rigidity losses. This is generally a consequence of micro-buckling of fibres. Indeed, the misalignment of fibers or the micro-defaults at fibers/matrix interface can strongly influence the emergence of micro-buckling. Therefore, compressive behaviour must be distinguished from tensile behaviour.

Drop in Young's modulus - or secant modulus because any damage appears in this direction - is a linear function of compressive stress. The linear coefficient is called $\gamma$. A similar approach has been introduced using the longitudinal strain:

$$
E_{11}^{\text {compression }} \approx E^{\text {secant }}=E_{11}^{\text {initial compression }}\left(1+\gamma E^{\text {secant }} \varepsilon_{11}\right)
$$

Therefore, Young's modulus is given by (16) if during calculation, a compressive load is detected.

$$
E_{11}^{\text {compression }} \approx E^{\text {secant }}=\frac{E_{11}^{\text {initial compression }}}{1-\gamma E_{11}^{\text {initial compression }} \varepsilon_{11}}
$$

Finally, the fact that the strain of rupture could be different in both cases of loading is also taken into account. Consequently, a new parameter is added to measure this compressive rupture strain rate. 


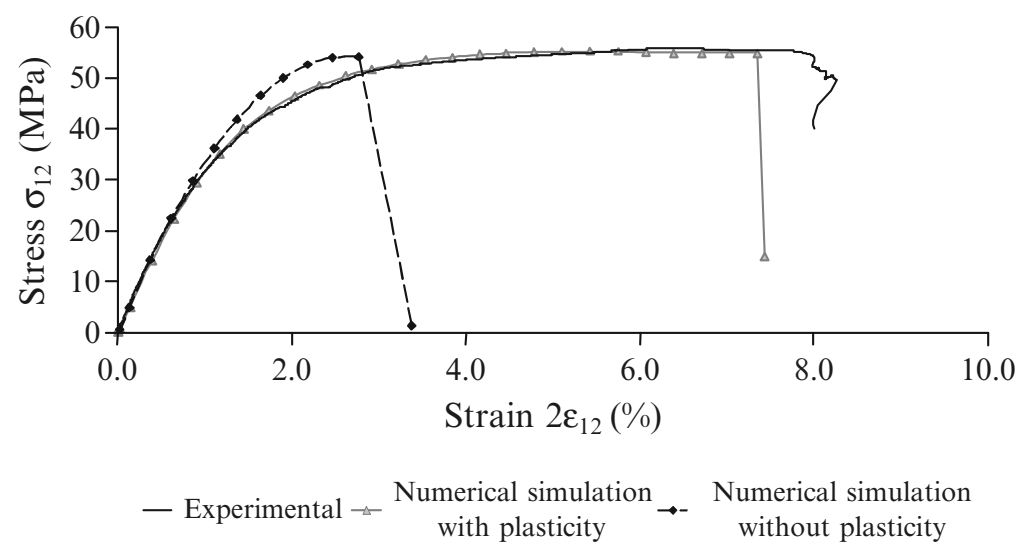

Fig. 14 Tensile comparisons on $[ \pm 45]_{2 S}$

The three sections that follow give three examples which explain the possible benefits of including one or other of the above improvements in the computation model for an application involving laminated components (fiber-matrix).

\subsection{Modeling the Ductility of the Resin in a Laminate}

The aim in this example is to visualize numerically the influence of matrix ductility on the overall behavior of a laminate [23]. On the basis of a tensile test performed on a glass E/epoxy $[ \pm 45]_{2 S}$ laminate with a fiber content of $60 \%$, we have compared, in the case where the strength of the matrix is dominant, the experimental stress/strain plot to a model for a composite material that includes elastic with damage behavior and a model which includes anelastic effects due to the ductility of the resin (Fig. 14). It is apparent that if anelastic phenomena are ignored, there is an error of approximately $50 \%$ in the shear strain. This case is an extreme one as the stacking of the studied material augmented shearing effects.

\subsection{Modeling the Effects of Strain Rate on the Behavior of the Laminate}

Tests [32] were performed to test the influence of the velocity of loading on a composite consisting of glass-E embedded in epoxy resin with $60 \%$ of fibres by volume. The several types of tests are: a tensile test on a $[0]_{4}$ laminate, a tensile test on a $[ \pm 45]_{\mathrm{S}}$ laminate, a tensile test on a $[ \pm 67.5]_{\mathrm{S}}$ laminate, a tensile test on a $[45]_{4}$ laminate and a compressive test on a $[0]_{6}$ laminate. The experimental 


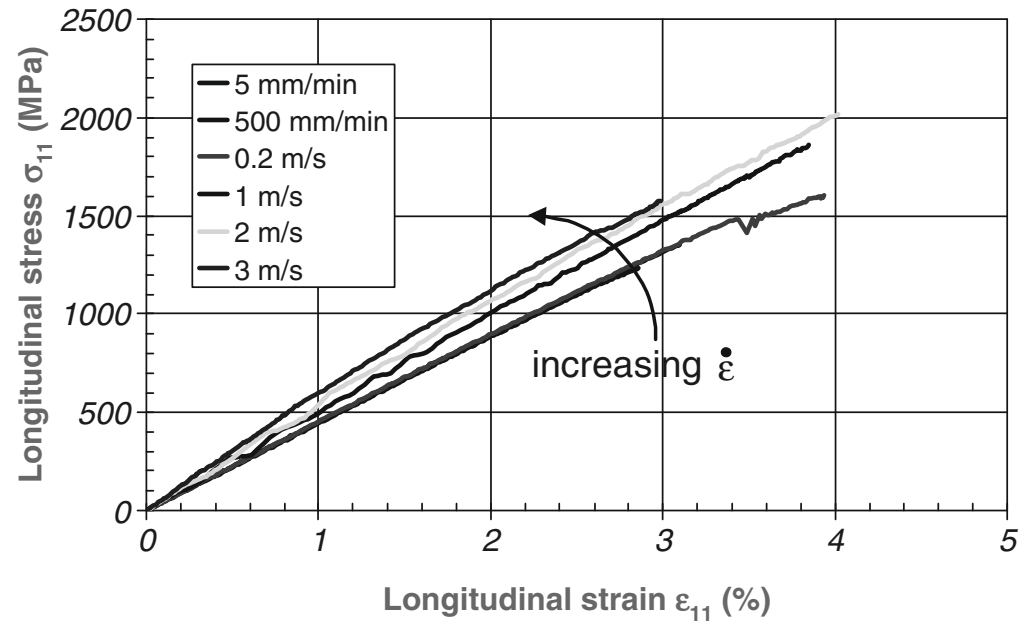

Fig. 15 Dynamic tensile tests on laminate $[0]_{4}$

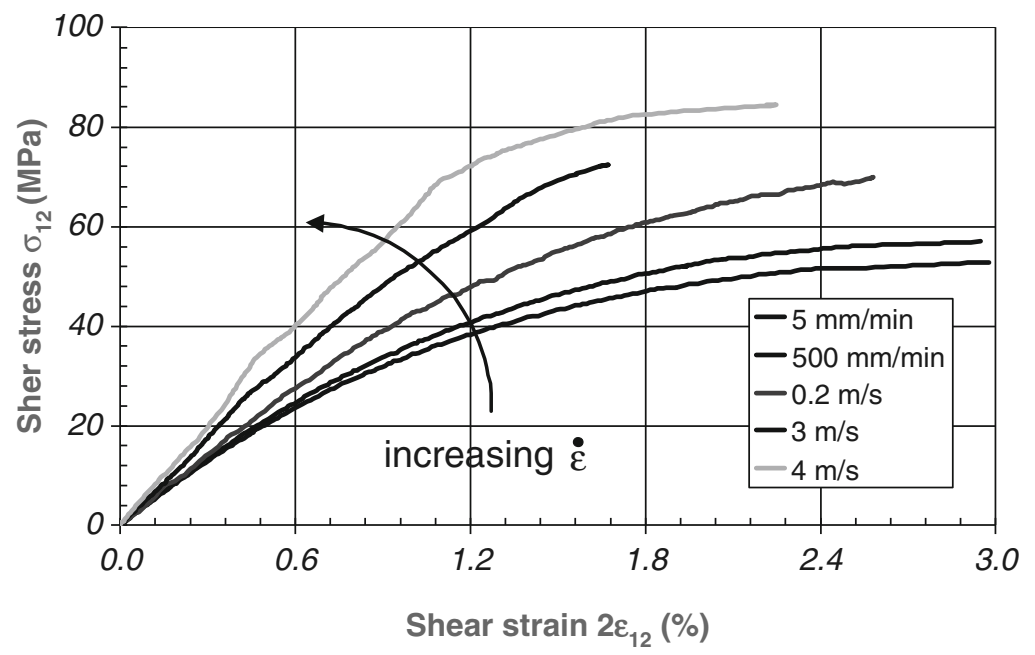

Fig. 16 Dynamic tensile tests on laminate $[ \pm 45]_{S}$

device used was a hydraulic jack. For each type of test, four velocities of loading were principally applied: $5,500 \mathrm{~mm} / \mathrm{min}, 0.2$ and $4 \mathrm{~m} / \mathrm{s}$. In this case, two essential conclusions resulted from the experimental tests. As shown in Figs. 15 and 16, the elastic moduli, the initial plastic flow stress and the failure stresses increase significantly beyond a certain strain rate threshold. These increases are of the order of between 30 and $300 \%$ depending on the parameters. In the direction of the fibers (Fig. 15), brittle-elastic behavior is conserved, but the modulus also changes significantly. In the other cases, there is a tendency for elastic-damage behavior to appear as a result of the influence of the strain rate. 
Fig. 17 Definition of viscous stress

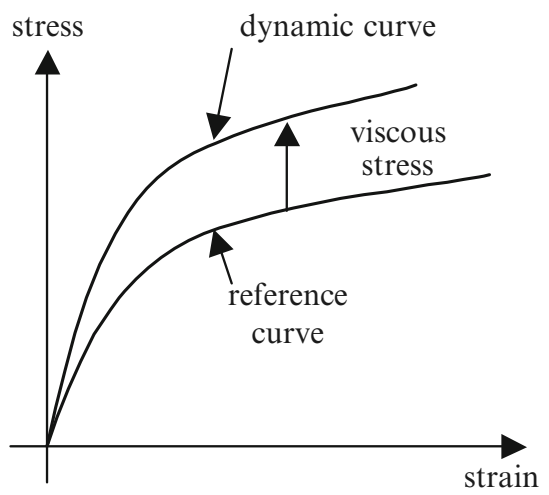

Consequently, the behavior may be in general described as elastic plastic viscous damage, on the basis of a reference behavior model. It is difficult to identify the type of behavior observed experimentally: it is neither, strictly speaking, viscoelastic nor viscoplastic. The proposed model has been combined with the viscous fluids approach [34]: the pseudo-viscoelasticity of the resin (in this case of the laminated composite) is taken into account using viscous stress which is added to the computed stress (Fig. 17). The behaviour is considered to be known at a reference rate.

The type of behavior observed in experiments is not easily identifiable: it represents neither visco-elasticity nor visco-plasticity. However, it is possible to approach the definition suggested by Lemaître and Chaboche [35] with regard to viscous fluids.

Indeed, epoxy resins, and more generally reticulate polymers, are sensitive to the strain rate during loads [36] viscosity primarily comes from the chain segment movements through barriers of energy potentials. These phenomena are all the more active (since they are thermally activated) as the vitreous transition temperature from epoxy resin is relatively low (between 50 and $150{ }^{\circ} \mathrm{C}$ ). We can be led to think that this rise in temperature, as a function of strain rate, brings about some microchanges in resin phases, which thus tend to become "soft" solids.

However, it should be noticed that strain rate influence on material behavior is certainly related to the resin dependence with respect to this strain rate, but is also closely related to the choice of components. Some studies on carbon/epoxy unidirectional laminates [37] have shown a strain rate insensitivity of the elastic moduli: carbon fibers have a Young modulus on average three times higher than that of glass-E fibers and thus inhibit the viscous effects of resin (in the elastic range).

Modeling results from the approach of viscous fluids [32]: the "pseudo-viscoelasticity" of resin (and in fact of laminated composite) are taken into account using a viscous stress, which is itself combined with the elastic stress (Fig. 17). Indeed, in experiments, it is always possible to determine the behavior at a given strain rate according to behavior at a reference strain rate.

In order to integrate the pseudo-visco-elastic nature of resin, the idea is to consider that dissipation's potential form is identical to the thermodynamic potential 
one, with the help of some characteristic functions of resin viscosity. Therefore, the stress tensor becomes as Eq. (19) according to the state law and the complementary law.

$$
\underline{\underline{\sigma}}=C^{0}: \underline{\underline{\varepsilon}}^{e}+\Theta: \underline{\underline{\varepsilon}}^{e} \quad(\Theta: \text { viscous tensor })
$$

The development of Eq. (19) for longitudinal, transverse and shear direction results in a description of elastic range. However, it is simplified owing to the approximation due to the dynamic rapid load type we are faced with. It can then be attributed to this general equation describing the elastic range:

$$
\underline{\underline{\sigma}}=C^{0}(I+F): \underline{\varepsilon^{e}} \quad(F: \text { viscous functions })
$$

In a phenomenological way, the material state (resin or composite) can always be given starting from its state in the reference configuration. We can thus suppose that the state for a given strain rate corresponds to the quasi-static state of another glass E/epoxy composite material from which material characteristics are different. Since the elastic moduli can increasingly evolve with the strain rate, this assumption results in postulating a damage progress faster than that of the reference case. It is possible to show that the constant damage evolution intrinsic to modeling [32], is a function root of the viscosity shear function:

$$
Y_{i j}(\dot{\varepsilon}) \approx \sqrt{\left(1+F_{12}(\dot{\varepsilon})\right)} Y_{i j}
$$

where $Y_{i j}$ prepresent each damage parameter

The previous assumption also suggests that the plasticity field moves accordingly (with an evolution of initial yield stress). Indeed, the initial yield stress undergoes an evolution of the same type as the elasticity moduli (22). Resin plasticity is coupled with the model by supposing that the plastic strain evolution is similar to the reference case. However, they are delayed since the material becomes increasingly "rigid".

$$
R_{0}(\dot{\varepsilon})=\left(1+F_{R}(\dot{\varepsilon})\right) R_{0}
$$

Finally, we put forward the additional assumption that the energy rate required to break the laminate (in the transverse and/or shear directions) is insensitive to the strain rate.

To verify that the primary theoretical behaviors had been accurately represented, so-called elementary validation was performed. This consisted of simulating the experimental tensile or compressive tests conducted under static and dynamic conditions. Figures 18 and 19 show the procedure and provide satisfactory correlation with the experiment. 


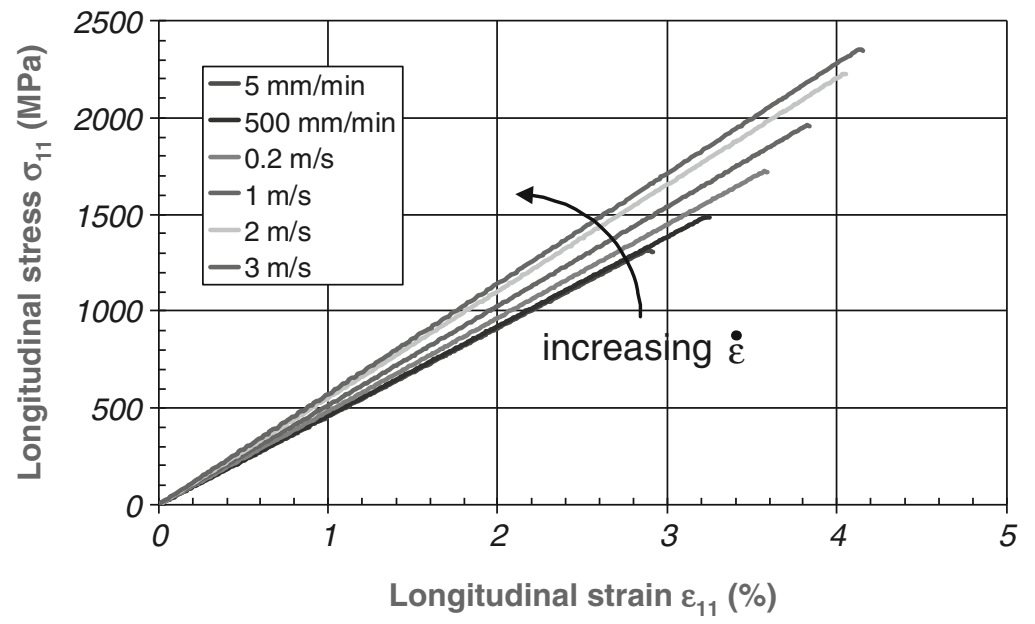

Fig. 18 Numerical dynamic tensile tests on laminate $[0]_{4}$

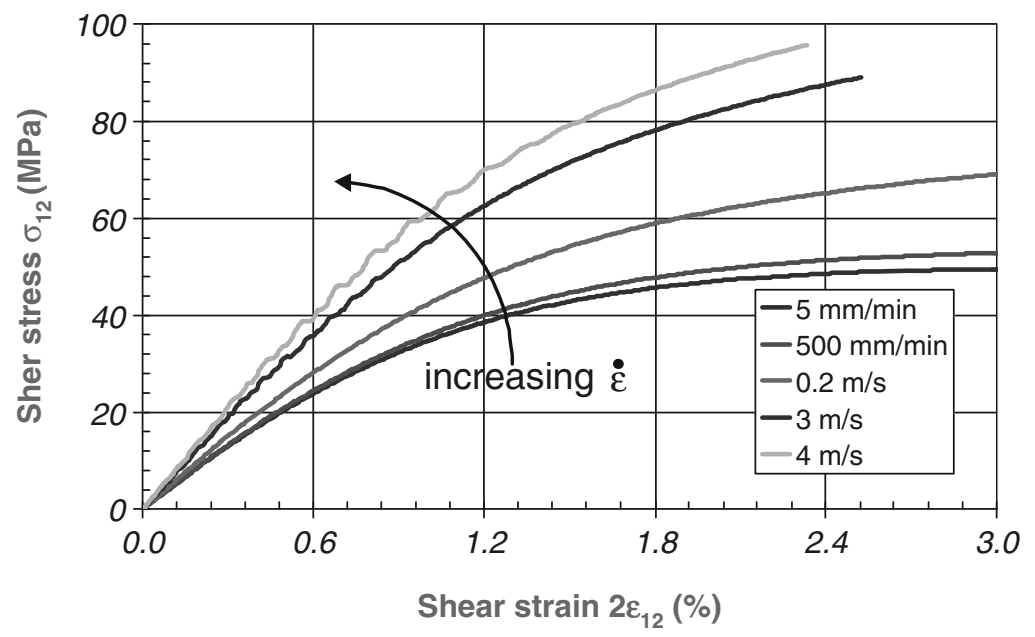

Fig. 19 Numerical dynamic tensile tests on laminate $[ \pm 45]_{S}$

\subsection{Taking Delamination into Account}

The above effects take place within the ply. However, as has been stated above, damage within the plies generates inter-ply cracking which greatly reduces the stiffness of the material. A methodology [38] was therefore developed which enables these effects to be included in a comprehensive impact calculation for multi-material composites and organic matrix laminates. The approach involves two stages. Initially, delamination in thin laminate structures is detected. The models 


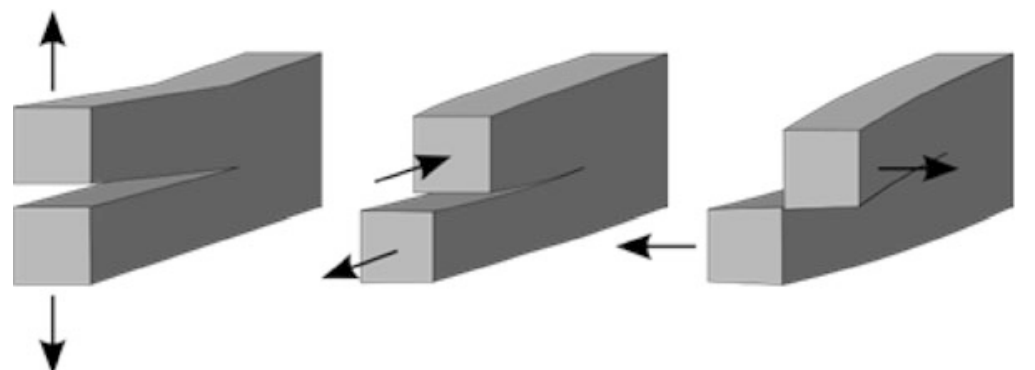

Mode I:

Mode II:

Mode III:

Fig. 20 Different fracture modes

which deal in a general manner with interface failures are very often 3D and model each ply with an element. The interface is also modeled by a variety of techniques depending on the method. In the case of large structures, these calculations require too many elements and are therefore too demanding of computing time. Our approach, which is based on a single multi-layer shell element developed previously, provides a powerful and effective alternative. While it is true that the method is unable to take account of mode I opening (Fig.20), because the stress which is normal to the surface of the element is not considered, this problem is a minor problem as in the case of most impact problems it is shear delamination which dominates.

The original feature of this research is the development of a numerical methodology which is able to detect delamination within a multi-layer shell element. The first stage is to introduce a thin layer with the characteristics of the resin used between the composite plies which are likely to undergo delamination. This layer, which is thin in relation to the plies in question, is considered as an interface which permits the application of criteria for the localization of delamination. Various concepts are used in order to analyze failure, namely the energy density at the epoxy interface, computed using the local stress tensor at the interface, and the Tsai-Hill criterion which can be applied for the stress tensor of the different layers. As delamination at the interface is very closely related to the damage of the adjacent composite plies, criteria of the same type as the Tsai-Hill criterion have been added in order to identify the different failure modes of the composite plies (cracking of the matrix, fibre/matrix shear) in both tensile and compression. The developed methodology consists of combining different criteria identified at the interfaces and in the associated plies. For the interface, the change in the energy density is computed during load application. In the event of a major reduction in this density (estimated on the basis of a percentage of the maximum amplitude by experimental calibration) and if the computed Tsai-Hill criterion is significant, the interface of the element is considered to have failed. Likewise, specific criteria are applied to the plies such that, if failure is detected in adjacent plies, the interface is automatically considered to have failed. This methodology takes account of the fact that interfacial damage 
depends on the cracking in the associated composite plies and that delamination is considered as an energy dissipation phenomenon as in fracture mechanics. This numerical processing has been applied to all the shell elements in stressed areas of the mesh at different time steps. The methodology also makes it possible to determine the critical stress level at which the interface fails in each element. The results take the form of a modification of the damaged surface within the structure over the course of time. The precision with which propagation of delamination is detected depends on the size of the constituent elements. A compromise must be made between the geometry of the shell element and the precision with which the model detects damage. Numerical processing was then applied in order to reproduce the mechanical effects generated by damage of the interface and the associated plies. This processing is based on a local modification of the mechanical characteristics of elements whose plies the methodology considers to be fractured. Effects are included in the code in a sequential manner: for each critical level of deflection that is attained, the elements whose plies have been identified as fractured have their characteristics modified. Computation then continues until the next critical deflection, which corresponds to fracture within other elements. Thus, by a cascade of localized reductions in the characteristics of the material, the aim is to influence the overall stiffness of the structure in order to ascertain the influence of these characteristics on the behavior of the structure as a whole. This modification in the critical phases of debonding causes fluctuations on the plots which may be filtered out subsequently. The ultimate objective is to obtain a good evaluation of the energy which is absorbed during impact. All the criteria-based analyses were processed using Mathlab, in this case combined with the PAMCRASH ${ }^{\mathrm{TM}}$ software which takes account of the modifications of the characteristic properties of the composite. Explicit formulation has been used to perform the finite element computation.

Various tests were conducted [31], in particular dynamic three point bending tests in the case of the laminated plates. A test conducted on a $\left[90_{2} / 0_{4} / 90_{2}\right]$ glass E/epoxy plate is presented here (Figs. 21 and 22). A velocity controlled jack was used for the dynamic experimental study. The damage mechanisms were validated by observations conducted with a high speed camera, strain gauges and displacement sensors. Two types of calculation were performed in order to demonstrate the validity of the developments. The first, which we have named comprehensive, does not take account of the mechanisms detected by the methodology in postprocessing, while the second, known as sequential, includes modifications of the intrinsic characteristics of the layers. The stress/strain curves shown on Fig. 23 are for a loading velocity of $5 \mathrm{~m} / \mathrm{s}$. The difference between the comprehensive calculation and the experimental result is considerable. The sequential calculation which includes the developments is already a considerable improvement as regards the estimation of the changes in energy. Its value is obvious in the case of the prediction of the overall behavior of the structure at the end of impact. It provides a very accurate estimate of the amount of energy absorbed, which is a fundamental variable in the framework of the impact design of structures. 
Fig. 21 Three point bending test

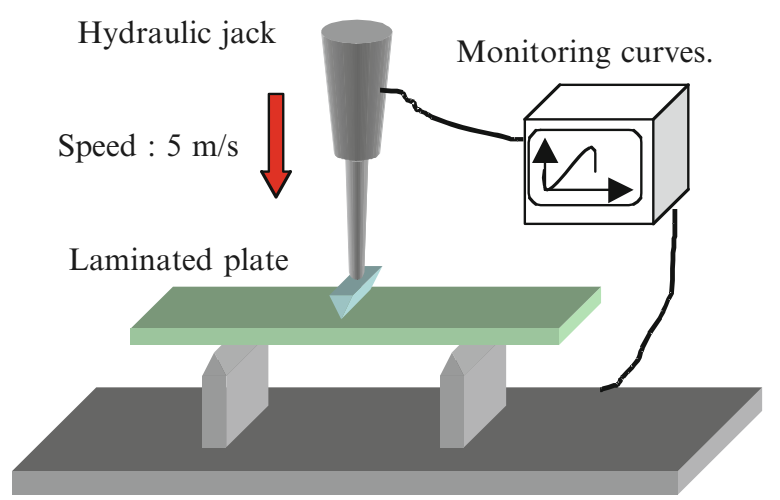

Vibration dampening base.

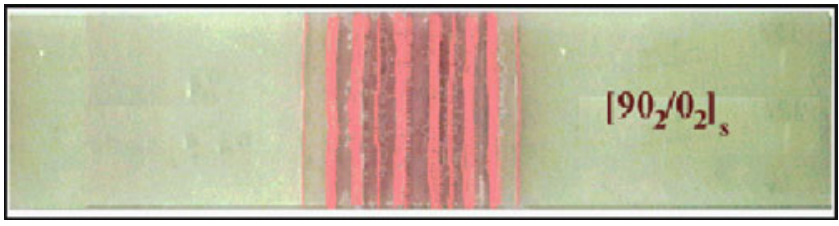

Fig. 22 Transverse stripes delamination (in red) of $\left[90_{2} / 0_{4} / 90_{2}\right]$ (top view)

\section{Energy ( $J$}

Velocity : $\mathbf{5 m} / \mathrm{s}$.

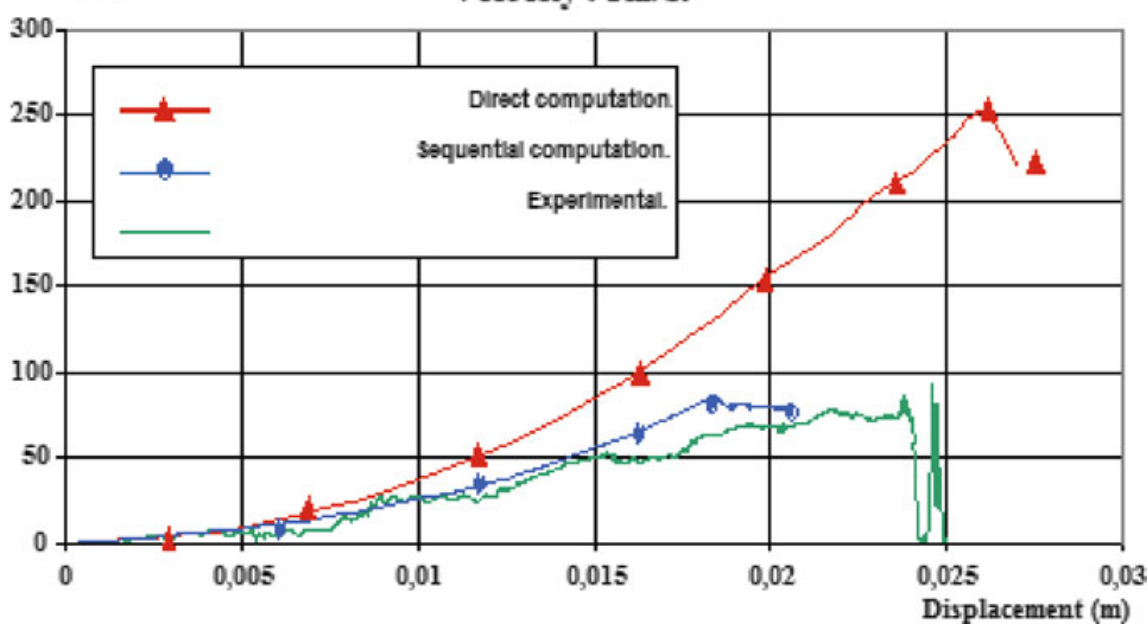

Fig. 23 Different curves of methodologies with or without delamination included compared to the experimental 


\subsection{Validation on a Composite Bonnet}

In order to illustrate this part, simulations of a pedestrian's head impact onto the front bonnet of a car (Fig. 4) have been achieved with a particular composite material [14]. Euro NCAP procedures exist now to measure the pedestrian safety. Euro NCAP's aim is to provide motoring consumers both drivers and the automotive industry with a realistic and independent assessment of the safety performance of some of the most popular cars sold in Europe. In this particular test studied here on a car bonnet, the objectives aimed are in fact to:

- Assure a minimal deflection of the engine hood during the head impact,

- Obtain an Head Injury Criteria (HIC) lower than 1,000 on the 2/3 of the area of the engine hood and lower than 2,000 on $1 / 3$ of the area when a specific head impactor hits the engine hood,

- Minimize the weight of the engine hood,

- Improve the numerical model of the engine hood by considering material damage or material strain rates.

Fiber Reinforced Plastic has been used for improving the pedestrian safety and permitting less injury. To design and optimize the shape of an engine hood, numerical simulations are widely used. Because of the entirely different material behavior of Fiber Reinforced Plastics compared with metals, new material models have to be used in the crash simulations. Existing material models for these materials show some deficits and therefore have to be improved. The strain rate material dependency and the delamination of the composite are implemented in the numerical simulation to obtain more accurate results. The influence on the results of secondary contacts between the hood and the engine which could happen during the impact with a pedestrian is also studied to forecast the potential damages on the hood. The experimental measurements have permitted to define the displacement values and, starting from decelerations, the HIC have been determined. The HIC is a measure of the likelihood of head injury arising from an impact. The HIC is used to assess safety related to vehicles. The variable is derived from the acceleration/time history of an accelerometer mounted at the centre of gravity of a dummy's head, when the dummy is exposed to crash forces. Figure 24 displays the experimental and numerical curves with and without the incidence of the strain rates for a given load case. The results are in perfect adequacy. In addition, taking into account the delamination, the damaged areas location have also been identified (Fig. 25).

The introduction of material laws optimized, of strain rates and of delamination contributes by numerical simulation to obtain a good behavior on the real industrial case. 


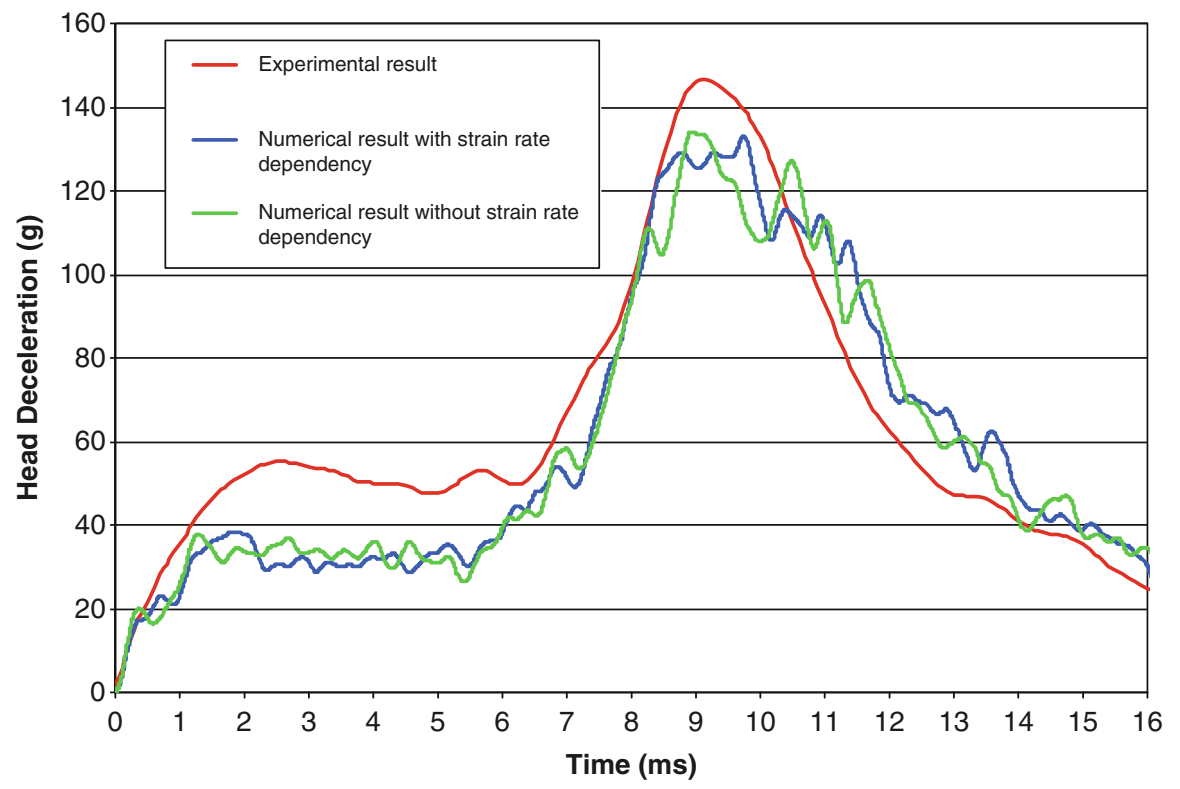

Fig. 24 Head impact deceleration curves (Courtesy: Daimler)

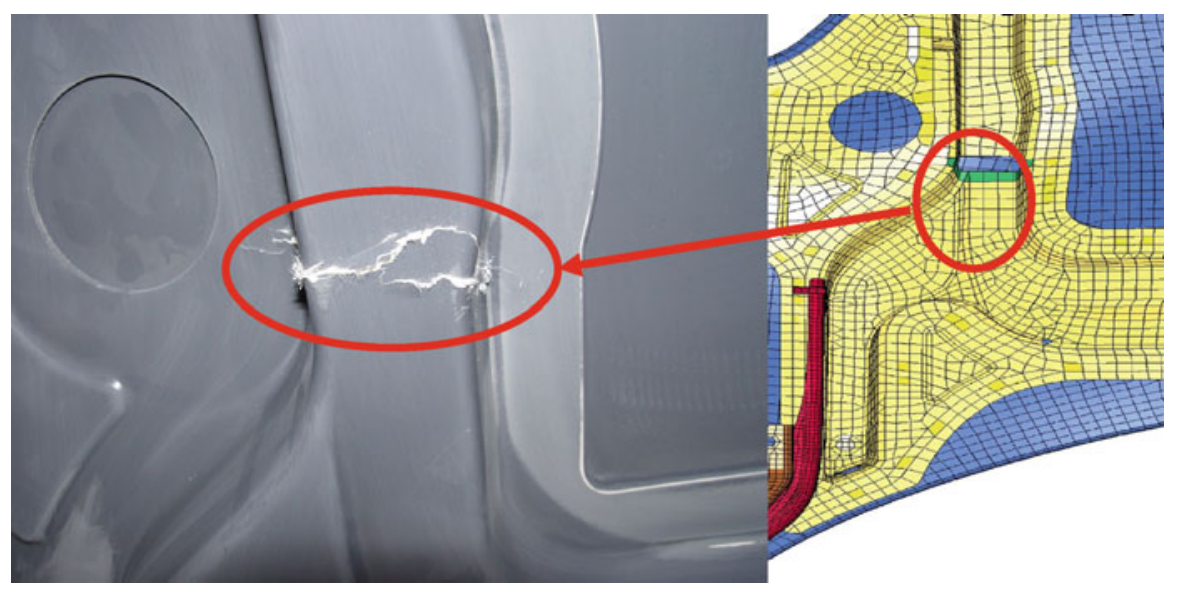

Fig. 25 Failure zone located on bonnet of a car (Courtesy: Daimler)

\section{Conclusion}

The few problem solving strategies hereby mentioned in this article illustrate the representation complexity in the field of composite materials simulation models whenever these are subjected to severe loadings such as impacts or shocks. Indeed, both the economic and normative constraints are to contribute, within the few years 
to come, to the general use of composite materials in the fields of transportation whatever they are. It therefore becomes a topical top-priority to bring about answers to contribute to the development of new tools or to the improvement of alreadyexisting items. A few examples have demonstrated the necessity to work at different levels and they have also permitted to illustrate the relevance of the developed models. Those studies are still going on in order to bring a contribution to the improvement of virtual prototyping tools and we hereby present two examples of resulting applications. One concerns the development of a similitude method to determine the real scale behavior starting from scaled-down structures. The first innovation is important. It allows us to study experimentally the large structures with scaled-down mock-up. This reduces costs. The second concerns the studies carried out with a car-manufacturer for the analysis of a pedestrian's head impact onto a front car-bonnet. This application demonstrates the relevance of developments made to allow better simulation of fracture phenomena in composite materials. An approach based on experimental campaigns led to the identification of material behaviors. This knowledge was then used to propose models capable of reproducing the phenomena.

Acknowledgements This research work results from numerous industrial cooperative schemes in the fields of aeronautic, automotive and railway technologies, more particularly with Daimler and ONERA, the European Community, the Ministry of Education, Research \& Technology, the North-Pas De Calais Region and the National Board for Scientific Research (CNRS) have also brought about a significant contribution to the development of this research work.

\section{References}

1. Corigliano A, Mariani S, Pandolfi A (2006) Numerical analysis of rate-dependent dynamic composite delamination. Compos Sci Technol 66(6):766-775

2. Flesher ND, Herakovich CT (2006) Predicting delamination in composite structures. Compos Sci Technol 66(6):745-754

3. Li S, Reid SR, Zou Z (2006) Modelling damage of multiple delaminations and transverse matrix cracking in laminated composites due to low velocity lateral impact. Compos Sci Technol 66(6):827-36

4. Jackson KE (1994) Workshop and scaling effects on composite materials and structures, Rapport NASA, Langley Research Center, Hampton, VA, NASA conference publication 3271

5. Simitses GJ (2001) Structural similitude for flat laminated surfaces. Compos Struct 51(2):191-194

6. Dormegnie D (2001) Contribution à l'étude de lois de similitude applicables au crash de structures composites stratifiées du type absorbeur d'énergie. Thèse de doctorat, Université de Valenciennes et du Hainaut-Cambrésis

7. Delsart D, Dormegnie D, Lassus V, Coutellier D (2002) Résistance au crash des structures d'hélicoptères, vers la réduction des coûts de conception. Revue Scientifique et Technique de la Défense 56:28-33

8. Dormegnie D, Coutellier D, Delsart D, Deletombe E (2003) Studies of scale effects for crash on laminated structure. Appl Compos Mater 10:49-61

9. Postec M, Deletombe E, Delsart D, Coutellier D (2008) Study of the influence of the number of inter-ply interfaces on the bearing rupture of riveted composite assemblies. Compos Struct 84:99-113 
10. Provost B, Boussu F, Coutellier D, Vallee D, Rondot F, Nussbaum J (2012) Comparison of Damages on 2D and 3D warp interlock fabric composite due to high velocity impact. International conference on mechanics of nano, micro and macro composite structures that will be held at the Politecnico di Torino, Department of Aeronautics and Space Engineering, Italy, 18-20 June 2012

11. Johnson AF, Holzapfel M (2006) Influence of delamination on impact damage in composite structures. Compos Sci Technol 66(6):807-815

12. Greve L, Pickett AK (2006) Delamination testing and modelling for composite crash simulation. Compos Sci Technol 66(6):816-826

13. Guédra-Degeorges D (2006) Recent advances to assess mono- and multi-delaminations behaviour of aerospace composites. Compos Sci Technol 66(6):796-806

14. Chick L (2006) Numerical simulation of advanced engine hoods with improved pedestrian safety, Diplôme de Recherche Technologique, Université de Valenciennes with Daimler AG

15. Coutellier D, Gauthier C, Rozycki P, Ravalard Y (1998) Numerical simulation of the tensile behaviour of multilayered multi-materials within an explicit software code. Eur J Mech Environ Eng 43(2):51-60

16. Coutellier D, Rozycki P (2000) New functionalities for PAMCRASH ${ }^{\mathrm{TM}}$ multi-layered multimaterial element. Compos Part A 31(8):841-851

17. Coutellier D, Geoffroy P, Walrick JC (2006) Presentation of a methodology for delamination detection within laminated structures. Compos Sci Technol 66(6):837-845

18. Grenêche R, Coutellier D, Ravalard Y (2005) A method for crash tests on laminated composite scaled down models. Appl Compos Mater 12(6):355-368

19. Allix O, Blanchard L (2006) Mesomodeling of delamination: towards industrial applications. Compos Sci Technol 66(6):731-744

20. Ladevèze P, Lubineau G, Marsal D (2006) Towards a bridge between the micro- and mesomechanics of delamination for laminated composites. Compos Sci Technol 66(6):698-712

21. De Borst R, Remmers J (2006) Computational modelling of delamination. Compos Sci Technol 66(6):713-722

22. Dacheux F (1993) Développement d'une technique de similitude indirecte sur modèles réduits; Application à l'étude du comportement en collision des véhicules de transport guidés, Thèse de Doctorat, Université de Valenciennes et du Hainaut Cambrésis

23. Farley GL, Wolterman RL, Kennedy JM (1992) The effects of crushing surface roughness on the crushing characteristics of composite tubes. J Am Helicop Soc 38:53-59

24. Hull D (1991) A unified approach to progressive crushing of fibre-reinforced composite tubes. Compos Sci Technol 40(4):377-421

25. Thornton PH (1979) Energy absorption in composite structures. J Compos Mater 13:247-262

26. Buckingham E (1914) On physically similar systems; illustration of the use of dimensional equations. Phys Rev 4:345

27. Gning P-B, Delsart D, Mortier J-M, Coutellier D (2010) Through-thickness strength measurements using Arcan's method. Compos Part B 41:308-316

28. Arcan M, Hashin Z, Voloshin A (1978) A method to produce uniform plane-stress states with applications to fiber reinforced materials. Exp Mech 18(2):141-146

29. Ladevèze P (1986) Sur la mécanique de l'endommagement des composites, JNC 5. Ed Pluralis, Paris, pp 667-683

30. Gauthier C (1996) Contribution à la modélisation du comportement en crash des structures stratifiées métal/composite. Développement d'un élément de coque multicouches multimatériaux, thèse de l'Université de Valenciennes et du Hainaut-Cambrésis

31. Walrick JC (1999) Contribution au développement d'une nouvelle méthodologie pour l'étude du délaminage dans les structures stratifiées composites: application à l'impact basse vitesse, thèse de l'Université de Valenciennes et du Hainaut-Cambrésis, Valenciennes

32. Rozycki P (2000) Contribution au développement de lois de comportement pour matériaux composites soumis à l'impact, Thèse de doctorat, Université de Valenciennes et du Hainaut Cambrésis 
33. Devillers JC, Coutellier D, Delsart D (2003) Determination of the interface characteristics of a glass-epoxy laminated composite by means of the ARCAN test procedure. 2nd international crashworthiness and design symposium 2003, vol 3, Lille, pp 1177-1186

34. Rozycki P, Coutellier D (2003) Improvement of the simulation tools dedicated to composite structures subjected to crash loads. In: Gogu G, Coutellier D, Chedmail P, Ray P (eds) Recent advances in integrated design and manufacturing in mechanical engineering. Kluwer Academic, Dordrecht, pp 105-116

35. Lemaitre J, Chaboche JL (1985) Mécanique des matériaux solides. Ed Dunod, Paris, Chapitre 1: pp 26-31, chapitre 4: pp 145-148

36. Chaboche JL (1995) Formalisme général des lois de comportements: applications aux métaux et polymères. In G'sell C, Haudin JM (eds) Introduction à la mécanique des polymères, Nancy, pp 119-140

37. Allix O, Deü JF, Ladevèze P (1999) A delay-damage meso-model for the prediction of localisation and fracture of laminates subjected to high-rate loading. European conference on computational mechanics, München, Germany

38. Coutellier D (2005) Innovation towards improved laminated structures design aid tools. In: Bramley A, Brissaud D, Coutellier D, McMahon C (eds) Advances in integrated design and manufacturing in mechanical engineering. Springer, Dordrecht, pp 269-280. ISBN $1-4020-3481-4$ 